\title{
Nanoparticle- and microparticle-based luminescence imaging of chemical species and temperature in aquatic systems: a review
}

\author{
Maria Moßhammer $^{1} \cdot$ Kasper Elgetti Brodersen ${ }^{1} \cdot$ Michael Kühl $^{1,2} \cdot$ Klaus Koren $^{3}$ (D)
}

Received: 7 November 2018 / Accepted: 20 December 2018 / Published online: 24 January 2019

(C) Springer-Verlag GmbH Austria, part of Springer Nature 2019

\begin{abstract}
Most aquatic systems rely on a multitude of biogeochemical processes that are coupled with each other in a complex and dynamic manner. To understand such processes, minimally invasive analytical tools are required that allow continuous, real-time measurements of individual reactions in these complex systems. Optical chemical sensors can be used in the form of fiber-optic sensors, planar sensors, or as micro- and nanoparticles (MPs and NPs). All have their specific merits, but only the latter allow for visualization and quantification of chemical gradients over 3D structures. This review (with 147 references) summarizes recent developments mainly in the field of optical NP sensors relevant for chemical imaging in aquatic science. The review encompasses methods for signal read-out and imaging, preparation of NPs and MPs, and an overview of relevant MP/NP-based sensors. Additionally, examples of MP/NP-based sensors in aquatic systems such as corals, plant tissue, biofilms, sediments and watersediment interfaces, marine snow and in 3D bioprinting are given. We also address current challenges and future perspectives of NP-based sensing in aquatic systems in a concluding section.
\end{abstract}

Keywords Optical sensing · Aquatic sciences $\cdot$ Chemical gradients Fluorescence Phosphorescence $\cdot$ Oxygen $\cdot \mathrm{pH} \cdot$ Nanomaterials

\section{Introduction}

The development and application of optical chemical sensor systems has increased immensely over the last decades and optical sensors are now key analytical tools in chemistry, biomedicine, biogeochemistry, environmental and aquatic science [1-5]. Tools to visualize chemical gradients in dynamic,

Maria Moßhammer and Kasper Elgetti Brodersen shared first authorship

Electronic supplementary material The online version of this article (https://doi.org/10.1007/s00604-018-3202-y) contains supplementary material, which is available to authorized users.

Michael Kühl

mkuhl@bio.ku.dk

$\triangle$ Klaus Koren

klaus.koren@bios.au.dk

1 Marine Biological Section, Department of Biology, University of Copenhagen, 3000 Helsingør, Denmark

2 Climate Change Cluster, University of Technology Sydney, Ultimo, NSW 2007, Australia

3 Aarhus University Center for Water Technology, Department of Bioscience - Microbiology, Aarhus University, 8000 Aarhus, Denmark difficult to access systems are in high demand [6, 7]. They help understand complex processes or the ability of natural systems to adapt to environmental changes such as increasing temperatures $[8,9]$, ocean acidification [9] or changes in salinity. Many of the used sensor systems rely on analytespecific changes in the optical properties, such as luminescence, which has advantages over electrochemical sensors. For example, luminescence-based sensor systems do not suffer from electromagnetic interferences $[10,11]$, are inexpensive $[11,12]$, easy to miniaturize [12] and optimize in terms of sensitivity $[11,13]$. They also have very robust read-out options, such as ratiometric or lifetime-based read-out of the analyte-dependent optical signal $[14,15]$. Especially, optical $\mathrm{O}_{2}$ sensors enjoy increasing popularity, due to a multitude of advantages over their electrochemical counterpart, the Clark electrode [15-18]. These include their tunable dynamic range towards trace $\mathrm{O}_{2}$ measurements, their easy implementation in chambers or well plates for respirometry, imaging at various spatial scales, multi-analyte detection and that no $\mathrm{O}_{2}$ is consumed during measurement [17].

Two very well established optical sensing techniques in aquatic science are based on i) fiber-optic sensors and ii) planar optodes. Fiber-optic sensors allow continuous, on-site monitoring of analyte dynamics [19] such as $\mathrm{O}_{2}$ [15, 20-23], 
$\mathrm{T}$ [23], or $p \mathrm{CO}_{2}$ [24]. They have a high spatio-temporal resolution and have been applied frequently in aquatic systems $[15,21-26]$ e.g. for water monitoring [15], monitoring of $\mathrm{O}_{2}$ and $\mathrm{pH}$ conditions in marine invertebrates [27, 28], aquatic eddy-correlation measurements [10, 15, 29], and profiling in marine sediments [22]. Such microsensors enable detailed point measurements but mapping of larger areas is time consuming, and the extrapolation to larger scales is difficult, if not impossible, in heterogeneous, dynamic systems [25]. In contrast, planar optodes facilitate $2 \mathrm{D}$ mapping of $\mathrm{O}_{2}[15,18$, $30-32$ ], $\mathrm{pH}$ values [31-35], $\mathrm{H}_{2} \mathrm{~S}$ [36], $p \mathrm{CO}_{2}$ [37-39], $\mathrm{NH}_{3}$ [40], $\mathrm{NH}_{4}{ }^{+}[41]$ and other chemical species over a planar area up to several $\mathrm{cm}^{2}$ in size. Planar optodes thus allow measurements over larger areas, as long as they can be brought in close, direct physical contact with the sample. They are frequently used to visualize chemical gradients in sediments [ 32 , $36,37,42,43]$, around worm burrows [31, 44] or root rhizospheres [44-47], but also in combination with cut coral samples and marine animals [48, 49]. More information on sensing with planar optode sensor foils and sampling gels can be found elsewhere [50].

Besides chemical mapping over planar cross sections through a sample or e.g. at the base of biomass growing on top of a planar sensor foil [51], there is demand for sensor systems capable of mapping the chemical landscape of spatially complex, flow-exposed surfaces. This can be accomplished by employing distributed sensing with optical indicators immobilized in sensor micro- and nanoparticles (MPs and $\mathrm{NPs}$; together referred to as optical sensor particles [OSPs]) in combination with luminescence imaging systems (Fig. 1c)
[25, 52-56]. Micro- and nanoparticle-based sensors can be coated or embedded into samples with a complex 3D structure (Fig. 1b). This allows for the determination of chemical gradients and dynamics, provided that they exhibit a specific and fully reversible interaction with the analyte, i.e., exhibit the characteristics of true sensors [1]. This review focuses on polymer-based, optical sensor NPs, but includes important MPs as well, which have been used successfully in aquatic sciences or hold a strong potential for future application.

\section{Imaging set-up}

Luminescence-based optical sensing with optical sensor particles (OSPs) relies on the same sensing principles as their fiber-optic or planar optode counterparts, such as luminescence quenching, Förster resonance energy transfer (FRET) or acid base equilibria [1]. A luminescent indicator dye, incorporated in the OSP is excited via an external excitation source. When returning from the excited state to the ground state via radiative de-excitation, photons of a higher wavelength than the excitation wavelength are emitted as luminescence; either via fast decaying fluorescence or slower decaying phosphorescence. There are also non-radiative de-excitation pathways, which are of importance for optical, chemical sensor systems. For example, $\mathrm{O}_{2}$ determination utilizes the non-radiative de-excitation of the indicator dye resulting from collisional quenching, which transfers excess energy to the quencher, i.e., molecular oxygen. Thus, luminescence is stronger in the absence of $\mathrm{O}_{2}$, but quenched in its presence [50]. a

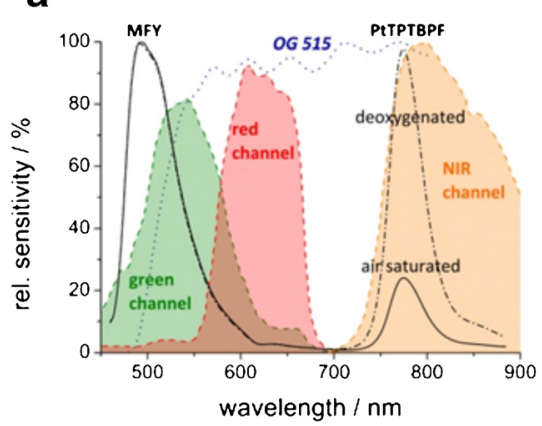

b

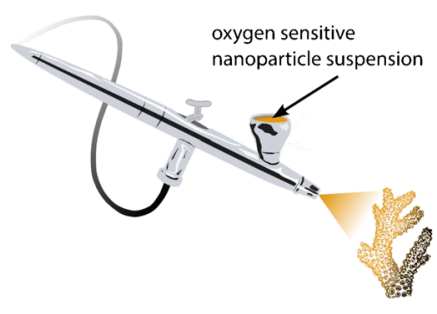

C

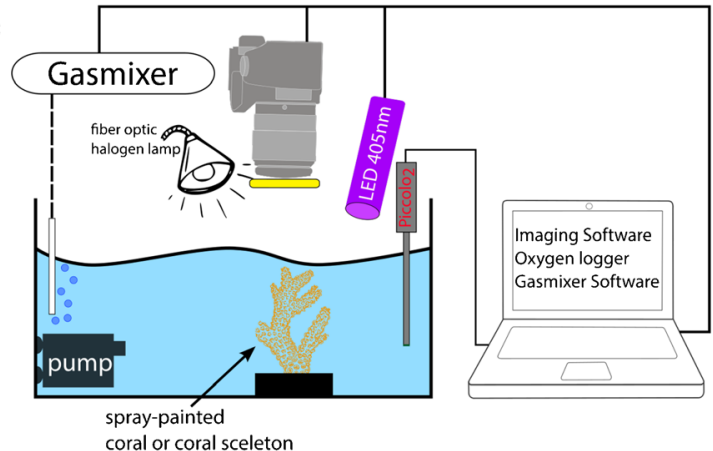

Fig. 1 Underlying principle of ratiometric luminescence imaging for particle-based optical sensing. a An example of sensor chemistry optimized for different channels of a camera system. A 2-CCD camera is used for sensing in the green, and NIR channel, whereas the blue channel overlaps with the excitation light. Upon blue excitation (458 nm), the reference dye (Macrolex Fluorescence yellow ${ }^{\circledR}$, MFY) emits in the green channel, whereas the $\mathrm{O}_{2}$ sensitive platinum(II) meso-tetra(4fuorophenyl)tetra-benzoporphyrin (PtTPTBPF) dye emits in the NIR channel of the camera. The luminescence intensity of the $\mathrm{O}_{2}$ sensitive dye is high under anoxic conditions (peak "deoxygenated") and is quenched in the presence of $\mathrm{O}_{2}$ (peak "air saturated"). A long-pass emission filter (OG 515) blocks light outside of the indicated spectral window from reaching the camera chip. [58] - Published by The Royal
Society of Chemistry. b The sample (here a coral fragment) is spraypainted with a nanoparticle suspension. $\mathbf{c}$ Example of an experimental set-up. A commercial SLR camera in combination with a long-pass filter (yellow) is used for imaging a spray-painted coral fragment. A LED is used as excitation sources for the two dyes (reference and indicator dye), while an external actinic light source is used for irradiation of the sample during experiments. The acquired RGB/NIR images can subsequently be split in separate channels for calculations of relevant image ratios using imaging-software. Reprinted from Sensors and Actuators B: Chemical, 237, Koren K., Jakobsen S. L., Kühl M., In-vivo imaging of $\mathrm{O}_{2}$ dynamics on coral surfaces spray-painted with sensor nanoparticles, 1095-1101, (c) 2016 Elsevier B.V. (2016), with permission from Elsevier [53] 
For spatial mapping with OSPs, optical sensor systems rely on imaging analyte concentration-dependent changes in photon emission with camera systems for ratiometric luminescence imaging $[31,32,57,58]$ or for lifetime-based luminescence imaging $[55,59,60]$. Pure luminescence intensity imaging suffers from various drawbacks. These include sensitivity to heterogeneities of the excitation light or indicator/ particle concentration over the sample, interference from background light, or fluctuations in the detector; all resulting in a unreliable read-out $[15,57]$.

\section{Ratiometric luminescence imaging}

Ratiometric imaging with optical sensor particles typically relies on a two-dye system; i) an inert reference dye, and ii) an analyte sensitive dye, both immobilized in a polymer matrix - either within the same particle or as individual particles. An elegant, but rarely used option employs a single dye with dual emission. There are e.g. indicator dyes, which show $\mathrm{O}_{2}$ sensitive phosphorescence as well as $\mathrm{O}_{2}$-insensitive fluorescence emission, which can be used for self-referencing [61-65]. In a two-dye system, ideally both reference and analyte sensitive dye are excited at the same wavelength and emit at different regions in the electromagnetic spectrum. This is then recorded with a camera systems via spectral separation, either using an image splitter or filter wheel in front of a monochrome camera [49], a multichannel RGB [31] or RGB-NIR camera system [32, 57]. When using commercial single-lens-reflex (SLR) cameras, the NIR filter is frequently removed to increase the sensitivity of the camera to red light. If a SLR camera is used for read-out, emission from reference and analyte-sensitive dye should ideally show no overlap and occur in different sensitive channels (blue, green, red) of the camera to avoid cross-talk between the channels [31, 57]. Interferences caused by this overlap can be avoided by the use of additional optical filters [14, 66]. When using a 2CCD camera an additional sensitive channel in the near infra-red (NIR) range is added, and NIR emitting dyes can be used as well (Fig. 1a) [57].

Post-acquisition, recorded images are split into the different channels, and ratios are calculated (Eq. 1 [31], Eq. 2 [32, 52]), resulting in a pixel intensity ratio image ' $R$ '.

$R=\frac{(\text { Channel }(\text { indicator dye })-\text { Channel }(\text { reference dye }))}{\text { Channel }(\text { reference dye })}$

$R=\frac{\text { Channel (indicator dye) }}{\text { Channel (reference dye) }}$

Due to this spectral overlap of the blue and green channel as well as the green and red channel, sometimes a change in analyte concentration can affect the intensity read out of the reference dye channel. To compensate for that the reference dye channel can be subtracted from the indicator dye channel (Eq. 1) [31]. Such interference can be further minimized by optimizing the used dye combination for minimal spectral overlaps and thus cross-talks between individual channels.

For calibration, ratio images are recorded at different defined analyte concentrations (Fig. 2a), from which a calibration curve can be obtained (Fig. 2b, shows an example of a calibration curve for $\mathrm{O}_{2}$ sensitive NPs). The calibration curve can be fitted with a function, which is subsequently used to calibrate ratio-images from actual experiments. This can be done using an image-analysis software (e.g. the freely available software ImageJ [32, 52, 53, 67]).

For an ideal $\mathrm{O}_{2}$-sensitive sensors (or in general sensors based on dynamic quenching [68]) a linear response can be described by the Stern-Volmer relation (Eq. 3) using either the luminescence intensity or lifetime in the absence $\left(\mathrm{I}_{0} ; \tau_{0}\right)$ or presence $(\mathrm{I}, \tau)$ of the quencher (Q). [Q] is the concentration of the quencher (in this case $\mathrm{O}_{2}$ ), and $\mathrm{K}_{\mathrm{SV}}$ the Stern-Volmer constant, which is a measure for the sensitivity of a dye towards the quencher $[15,68,69]$.

$\frac{I_{0}}{I}=\frac{\tau_{0}}{\tau}=1+K_{S V}[Q]$

Ideally, the correlation between $\mathrm{I}_{0} / \mathrm{I}$ or $\tau_{0} / \tau$ and $[\mathrm{Q}]$ is linear, however, in reality when static and dynamic quenching occurs simultaneously, and the polymer matrix influences the local quenchability of the dye, the correlation deviates from linearity $[15,68,69]$. This non-linear correlation can be described using the so called "two-Site model" (Eq. 4), which additionally takes the fractions of the total emission from differently quenched sites $\left(f_{1}\right.$ and $\left.f_{2}\right)$ as well as the respective quenching coefficient $\left(\mathrm{K}_{\mathrm{SV}}{ }^{1}\right.$ and $\left.\mathrm{K}_{\mathrm{SV}}{ }^{2}\right)$ into account $[15,70$, 71]. While the Two-Site model actually describes luminescence intensities, it can also be used to fit luminescence decay time dependencies on analyte concentration $[61,72]$. In the latter case, the model describes a double-exponential decay, where both decay functions are different due to non-identical accessibility of the sites to the quencher, which are therefore described individually. The Two-Site model can be further extended to include additional quenching sites and decay functions, however, in practice Eq. 4 provides a good description of experimental calibration data [71] and is frequently used.

$\frac{I}{I_{0}}=\frac{\tau}{\tau_{0}}=\frac{f_{1}}{1+K_{S V}^{1}[Q]}+\frac{f_{2}}{1+K_{S V}^{2}[Q]}$

Calibrated images can be color-coded to better visualize the analyte distribution at a certain time point, the formation of hotspots, or the development of gradients over time. Ratiometric luminescence imaging can be realized with 

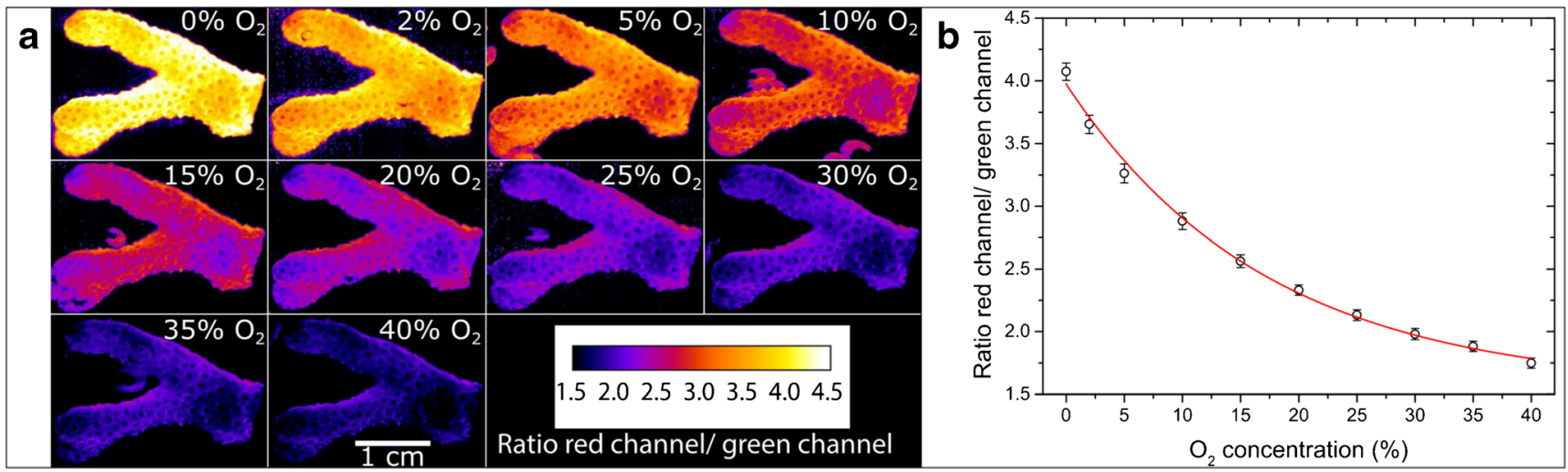

Fig. 2 Schematic representation of the calibration process using a ratiometric luminescence imaging system. a Color-coded ratio images of the spray-painted coral skeleton fragment exposed to different $\mathrm{O}_{2}$ concentrations. b The calibration curve fitted using 3 regions of interest of the spray-painted coral skeleton fragment plotted against the respective

$\mathrm{O}_{2}$ concentration. Reprinted from Sensors and Actuators B: Chemical, 237, Koren K., Jakobsen S. L., Kühl M., In-vivo imaging of $\mathrm{O}_{2}$ dynamics on coral surfaces spray-painted with sensor nanoparticles, 1095-1101, (C) 2016 Elsevier B.V. (2016), with permission from Elsevier [53]

relatively inexpensive camera setups and largely corrects for heterogeneous luminophore concentrations or excitation light distribution $[31,32,69]$. However, ratiometric imaging can be prone to light scattering and background luminescence artefacts [61], and artefacts due to differential binding, leaching or bleaching of the reference and indicator reporting dye [57, 73].

\section{Luminescence lifetime-based imaging}

Luminescence lifetime imaging monitors the analytedependent decay time of the indicator luminophore [60]. The time dependence of emission can be described by an exponential decay, where the time constant is expressed as luminescence lifetime $(\tau)$. In order to get the decay function,

\section{Time-Domain Mode}

\section{a Rapid Lifetime Determination}

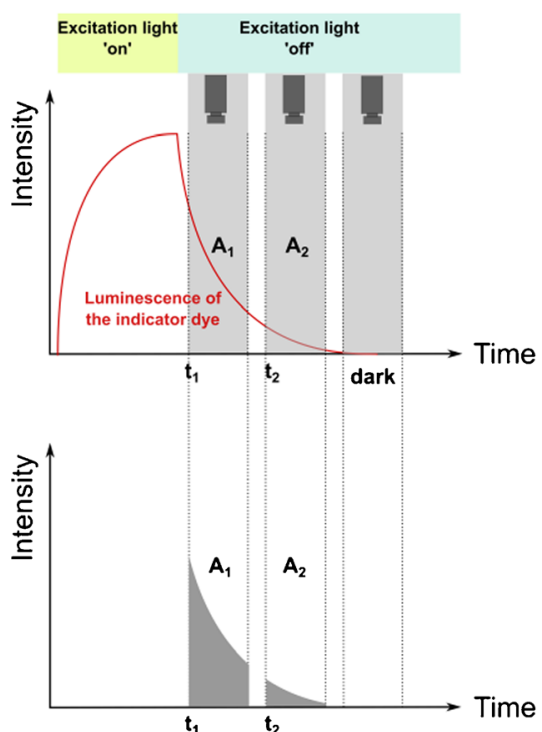

b

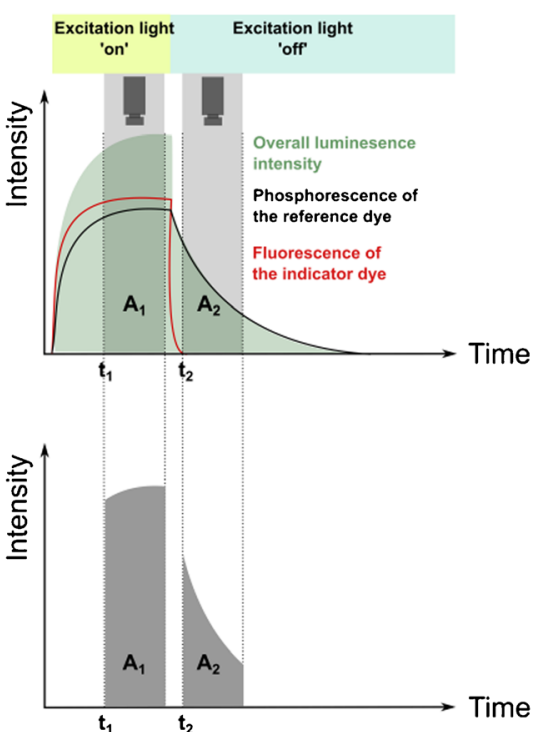

\section{Dual Lifetime Determination}

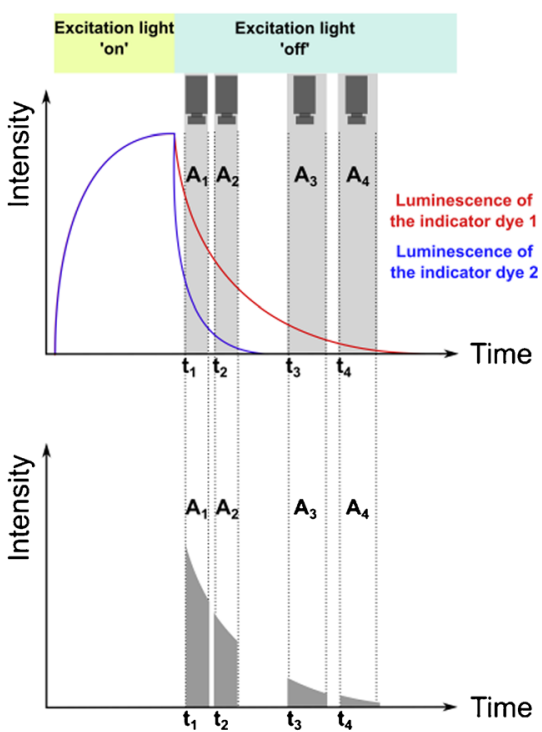

Fig. 3 Time-domain luminescence lifetime imaging. a Rapid lifetime determination (RLD) determines the luminescence lifetime by imaging two time windows during the decay phase of the indicator dye. A third window can be acquired after the complete decay of the luminophore to subtract background luminescence. b Dual lifetime referencing (DLR) uses a reference dye of longer lifetime and an indicator dye of shorter lifetime. Images are acquired at the time points $t_{1}$ (during excitation) and $t_{2}$ (during the decay phase) over a certain time interval (grey box), which is integrated ( $A_{1}$ and $A_{2}$ ). c Dual lifetime determination (DLR) can determine the luminescence lifetime of two indicator dyes. Two time windows are imaged during the overlapping decay of both luminophores, and two time windows are taken after the complete de-excitation of the shorter-lived luminophore. In all three cases, the integrated luminescence signals in the time intervals are used to calculate the luminescence lifetime $\tau$ (see Eq. 5) 
the luminophore is excited by a short light pulse, and the luminescence decay as a function of time is subsequently measured. This can be done either with photon counting detectors, while scanning over the field of view or via dedicated lifetime imaging systems [74]. Thus, luminescence lifetime-based imaging systems typically rely on a precisely pulsed light source and high speed camera systems with fast gate-able shutters [14]. Luminescence lifetimes can be determined either in the time-domain (Fig. 3) or the frequency-domain (Fig. 4) [16].

\section{Time-domain measurements}

Time-domain measurements of luminescence lifetimes use short, square-shaped light pulses (e.g. from a pulsed LED or laser $[69,75])$ to excite the luminophore. The luminescence decay over time is either recorded via timecorrelated single-photon counting or via acquisition of images at defined times after the excitation pulse. In order to detect lifetimes in the ns range, cameras with very short exposure times are required [76]. Several variations of this measuring scheme are used (Fig. 3, modified from Stich et al. [77]):

i) Rapid lifetime detection (RLD; Fig. 3a) records luminescence in two time windows of equal length, measured at specific times $\left(t_{1}\right.$ and $\left.t_{2}\right)$ in the emission phase. Lifetimes are calculated from Eq. 5 [77] by integration of the luminescence signal in each time window [16, $69,77]$. A major advantage of RLD is that it is not

\section{Frequency-Domain Mode}

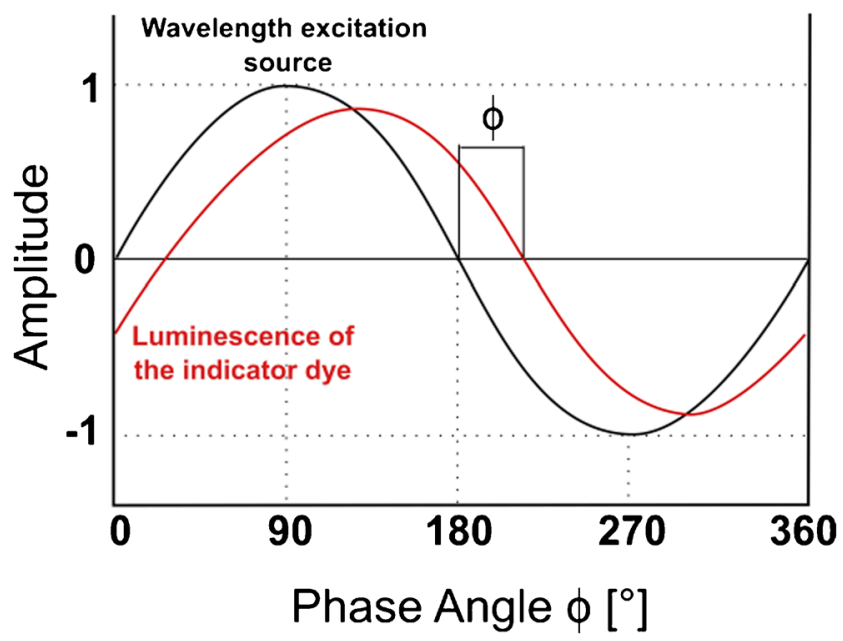

Fig. 4 Luminescence lifetime imaging based on frequency-domain measurements. The sinus-modulated light source excites the luminophore, which emits photons in a phase-shifted sinus-modulated wave. The phase shift $(\phi)$ is used to calculate the luminescence lifetime, $\tau$ (see Eq. 6) affected by photo-bleaching, as $\mathrm{A}_{1}$ and $\mathrm{A}_{2}$ are reduced similarly, and this is compensated for via the ratio [77]. The detection method for RLD is always gated [16].

$$
\tau=\frac{t_{2}-t_{1}}{\ln \frac{A_{1}}{A_{2}}}
$$

ii) Dual lifetime referencing (DLR; Fig. 3b) employs two luminophores, an indicator dye with a short lifetime (e.g. $<100 \mathrm{~ns}$ ) and a reference dye with a longer lifetime. Both dyes are excitable at the same wavelength with overlapping emission spectra, but different luminescence decay times. The camera records two time windows, one during the excitation phase $\left(\mathrm{t}_{1}\right.$; emission from both luminophores) and one in the decay phase $\left(\mathrm{t}_{2}\right.$; only emission from reference dye). The ratio of the two time-integrated luminescence signals, $\mathrm{A}_{1}$ and $\mathrm{A}_{2}$, can be correlated to the analyte concentration. The first window (signal) contains both the phosphorescence and fluorescence signal, while the second window only records the phosphorescence signal as the fluorescence already decayed. However, the individual lifetimes of each luminophore are not determined by this method.

iii) Dual lifetime determination (DLD, Fig. 3c) is similar to RLD but done simultaneously for two luminophores with decay times differing by a factor of at least 10 . A total of four time windows (and four integrated time intervals) are measured. $t_{1}$ and $t_{2}$ overlap with the decay curve of both luminophores and have the same time span, whereas $t_{3}$ and $t_{4}$ overlap exclusively with the decay curve of the longer-lived luminophore. $t_{3}$ and $t_{4}$ last for the same time interval as well, which can however differ from $t_{1}$ and $t_{2}$. Lifetimes are calculated using Eq. 5 for each luminophore $[16,77]$.

Imaging luminescence lifetime instead of luminescence intensity has the advantage that the signal exclusively depends on recording an analyte-dependent, time-dynamic signal change. This signal is not dependent on the absolute luminophore concentration as long as enough luminescence is generated to enable a sufficient signal to noise ratio in such measurements. Leaching, bleaching or varying thickness of the sensor-layer, inhomogeneous illumination by the excitation source [16, 74], or light scattering effects [77] are thus minimal. Additionally, background luminescence does not interfere, as long as the lifetime of the interfering compound differs from the luminophore lifetime [60].

Frequently used camera systems for time-domain luminescence imaging use fast gate-able CCD cameras such as the PCO SensiCam series (pco.de). This timedomain based camera system series has been discontinued from the company but is still widely used in research. The 
'SensiCam qe' $[48,56,78,79]$ is a fast gate-able, cooled 12 bit CCD camera, which allows exposure times as low as $500 \mathrm{~ns}$ up to $3600 \mathrm{~s}$, has a high spectral sensitivity even in the NIR range, and has a resolution $1376 \times 1040$ pixel resolving $6.45 \mu \mathrm{m} \mathrm{pixel}^{-1}$. The SensiCam SensiMod is also frequently applied [60, 80, 81], it has similar imaging characteristics but a lower pixel resolution of $640 \times 480$ pixels [59, 60] Alternatively, time-correlated photon counting imaging systems for fluorescence (FLIM) or phosphorescent (PLIM) lifetime imaging are frequently used in connection with microscopic imaging $[74,82,83]$.

\section{Frequency-domain measurements}

Frequency-domain measurements of luminescence lifetimes use a harmonically modulated light source instead of a light pulse for excitation of the luminophore (Fig. 4). This results in a modulated luminescence emission, which is phase-shifted in regard to the excitation wavelength according to the luminescence lifetime, but follows the excitation frequency [16, 76, 77]. Possible light sources described in literature encompass modulated laser diodes, LEDs or super-continuum lasers [84-86]. Frequency-domain-based lifetime imaging is fast and accurate but requires fast cameras that can be frequency modulated [84]. For a mono-exponential decay of the luminescence lifetime, $\tau$ can be calculated via the phase shift $(\phi)$ and the constant modulation frequency $(f)$ as [16].

$\tan \phi=2 \cdot \pi \cdot f \cdot \tau$

This method is widely used as a readout method in fiberoptic optode meters, while it is rarely employed for luminescence lifetime imaging. Cameras enabling frequency domain based imaging are relatively new and only few commercial systems are available: The pco.flim camera system (pco.de) [76] can measure luminescence lifetimes of $100 \mathrm{ps}-100 \mu \mathrm{s}$ with a pixel resolution of $1008 \times 1008$ pixels and selectable exposure times from $10 \mathrm{~ns}$ to $10 \mathrm{~s}$. The Toggle camera system (lambertinstruments.com) can measure luminescence lifetimes in the ps - $\mu$ s range at up to 30 lifetime images per second at a pixel resolution of $504 \times 512$ pixels. Both camera systems can be used flexibly with macro objectives or mounted on a microscope.

Sensor nanoparticles and microparticles For optical sensing, the sensor chemistry is incorporated into polymer OSP. Depending on the read-out method such OSP can contain a single, analyte-sensitive luminescent dye (for lifetime-based read-out), or an analyte-sensitive dye either in combination with a donor dye, or a reference dye (for ratiometric readout). The added donor dye can increase the measured luminescence intensity. [15]. Table 1 lists analyte sensitive dyes or 'indicator dyes' that have been used in literature for OSPbased optical sensing and their abbreviations. Their use and specific preparation are summarized in the supplementary material. Depending on the application, other additives can be incorporated in the sensor particles to modify e.g. their magnetic, optical or surface properties. Superparamagnetic nanoparticles $[25,87-89]$ can thus be included in order to magnetically control the OSPs. Also scattering agents such as hydrophilic $\mathrm{TiO}_{2}$ can be incorporated in the OSPs enhancing their optical brightness [89]. Tables 2, 3, 4, and 5 summarize different polymer-based optical particles, their composition, specifics, preparation and application. We note that some listed OSPs have not yet been used in aquatic systems, but showed promising results and no cytotoxicity e.g. in human or animal cell cultures. These particles might thus also be suitable for future aquatic and environmental applications.

For application of OSPs in aquatic systems, it is important that neither the dye(s) nor the polymer matrix show toxicity effects or chemically alter the surrounding environment. Silica is e.g. frequently used to incorporate toxic indicator dyes in OSPs enhancing their biocompatibility [3]. The dyes must not leach out of the matrix and need to be immobilized in the OSPs. The particles should not aggregate, which means that the surface properties of the OSPs may need modification such as, e.g. the deposition of an inert material as shell on the surface [90] or the functionalization of the surface with polar groups [1]. The OSPs should be stable for several days to e.g. allow long-term measurements, sample acclimation, particle binding or perfusion after exposing it to the OSPs. Therefore, photo-bleaching needs to be taken into consideration as well. An additional challenge for applying OSPs in aquatic habitats is the strong dynamics of environmental parameters. These comprise temperature (polar regions to hot springs), salinity (freshwater to hypersaline waters and intertidal zones), pressure and solar irradiance (deep-sea to surface waters), water movement (stagnant ponds to fast streams), and viscosity (water, sediments and tissues) [15].

Apart from their ability to measure and visualize complex spatio-temporal chemical gradients via distribution of OSPs over complex 3D structures, OSPs have other advantages such as: i) a high surface-to-volume ratio, making them fast responding and highly accessible for analytes, ii) good signal-to-noise ratios due to high dye loading concentrations in NPs, iii) possibility to load multiple indicator dyes into particles or mix OSPs with different indicators, and vi) optimization of particle binding or perfusion in samples via surface modification of OSPs [91].

There are various methods to produce polymeric, optical MPs and NPs. The six most frequently employed techniques, namely i) precipitation, ii) microemulsion polymerization, iii) mini-emulsion solvent evaporation (MESE), vi) core-shell staining, v) sol-gel and vi) spray drying preparation are described below (Fig. 5), together with their specific advantages 
Table 1 Abbreviations and full chemical name of indicator and reference dyes, solvents and matrix materials used in optical sensor particle preparation

\begin{tabular}{|c|c|c|c|}
\hline Abbreviation & Chemical name & Analyte / Use & Reference \\
\hline PtTFPP & platinum(II)-5,10,15,20-tetrakis-(2,3,4,5,6-pentafluorphenyl)-porphyrin & $\mathrm{O}_{2}$ & {$[52,53]$} \\
\hline $\begin{array}{l}\operatorname{Ir}\left(\mathrm{C}_{\mathrm{S}}\right)_{2}(\mathrm{acac}) \\
\text { PdTPTBPF }\end{array}$ & $\begin{array}{l}\text { iridium(III) acetylacetonato-bis(3-(benzothiazol-2-yl)-7-(diethylamino)-coumarin } \\
\text { palladium(II) meso-tetra(4-fluorophenyl)tetrabenzoporphyrin }\end{array}$ & $\begin{array}{l}\mathrm{O}_{2} \\
\mathrm{O}_{2}\end{array}$ & {$[88]$} \\
\hline РtТРТВPF & platinum(II) meso-tetra(4-fluorophenyl)tetrabenzoporphyrin & $\mathrm{O}_{2}$ & \\
\hline PdTPTBP & palladium(II) meso-tetraphenyltetrabenzoporphyrin & $\mathrm{O}_{2}$ & \\
\hline PtOEPK & platinum octaethylporphine keton & $\mathrm{O}_{2}$ & {$[92]$} \\
\hline$\left[\mathrm{Ru}(\mathrm{dpp})_{3} \mathrm{Cl}_{2}\right]$ & ruthenium (II)-tris-4,7-diphenyl-1,10-phenanthroline dichloride & $\mathrm{O}_{2}$ & [93] \\
\hline PtOEP & platinum(II) octaethylporphyrin & $\mathrm{O}_{2}$ & {$[55]$} \\
\hline $\mathrm{HPTS}(\mathrm{DHA})_{3}$ & 1-hydroxypyrene-3,6,8-tris-bis(2-ethylhexyl)sulfonamide & $\mathrm{pH}$ & {$[54]$} \\
\hline $\mathrm{CNF}$ & 5- and 6-carboxynaphthofluorescein & $\mathrm{pH}$ & [93] \\
\hline $\begin{array}{l}\text { CHFOE } \\
\text { HPTS }(\mathrm{OA})_{3}\end{array}$ & $\begin{array}{l}\text { 2'-chloro-7'-hexylfluorescein octadecylester } \\
\text { 1-hydroxypyrene- 3,6,8-tris-octylsulfonamide }\end{array}$ & $\begin{array}{l}\mathrm{pH} \\
\mathrm{pH}\end{array}$ & [94] \\
\hline $\begin{array}{l}\text { DClFE } \\
\text { ClHFE }\end{array}$ & $\begin{array}{l}2^{\prime}, 7^{\prime} \text {-dichlorofluorescein octadecylester } \\
\text { 2'-chloro-7'-hexylfluorescein octadecylester }\end{array}$ & $\begin{array}{l}\mathrm{pH} \\
\mathrm{pH}\end{array}$ & {$[95]$} \\
\hline $\mathrm{FE}$ & fluorescein octadecylester & $\mathrm{pH}$ & \\
\hline DHFE & $2^{\prime}, 7^{\prime}$-dihexylfluorescein octadecylester & $\mathrm{pH}$ & \\
\hline DClFA & 2',7'-dichloro-5(6)- $N$-octadecylcarboxamidofluorescein & $\mathrm{pH}$ & \\
\hline MCIFA & 2'-chloro-5(6)- $N$-octadecyl-carboxamidofluorescein & $\mathrm{pH}$ & \\
\hline FA & $5(6)-N$-octadecyl-carboxamidofluorescein & $\mathrm{pH}$ & \\
\hline DHFA & $2^{\prime}, 7^{\prime}$-dihexyl-5(6)-N-octadecyl-carboxamidofluorescein & $\mathrm{pH}$ & \\
\hline DDodF & $2^{\prime}, 7^{\prime}$-didodecylfluorescein & $\mathrm{pH}$ & \\
\hline Tb-THBA & Terbium(III) tris[(2-hydroxybenzoyl)-2-aminoethyl]amine & $\mathrm{T}$ & [96] \\
\hline $\operatorname{Ir}(\text { ppy })_{2}$ carbac & $\begin{array}{l}\text { di(2-phenylpyridinato- } C 2, N)\{1 \text {-(9H-carbazol-9-yl)-5,5-dimethylhexane- } \\
\text { 2,4-dione }\} \text {-iridium(III) }\end{array}$ & $\mathrm{T}$ & {$[97]$} \\
\hline $\mathrm{Eu}(\mathrm{tta})_{3}$ & europium(III) tris(thenoyltrifluoroacetonate) trihydrate & $\mathrm{T}$ & [94] \\
\hline BME-44 & $\begin{array}{l}\text { 2-dodecyl-2-methyl-1,3-propanediylbis }[N \text {-[5'nitro(benzo-15- } \\
\text { crown-5)-4'-yl]carbamate] }\end{array}$ & $\mathrm{K}^{+}$ & [98] \\
\hline ETH 5350 & 9-dimethylamino-5-[(2-octyldecyl)imino]-benzo[a]phenoxazine & $\mathrm{K}^{+}$ & [93] \\
\hline BODIPY & borondipyrromethenes & - & \\
\hline FI 3 & Fluoroionophore 3; a aza-crown ether coupled to a BODIPY & $\mathrm{K}^{+}$ & {$[99,100]$} \\
\hline MY / MFY & Macrolex yellow & $\begin{array}{l}\text { Reference dye, } \\
\text { donor dye }\end{array}$ & \\
\hline $\mathrm{Bu}_{3} \mathrm{Coum}$ & Butyl-substituted coumarin & Reference dye & {$[32,67]$} \\
\hline Perylene & & Reference dye & {$[54]$} \\
\hline OEP & octaethylporphyrin & Reference dye & {$[92,101]$} \\
\hline Alexa Fluor 488 & & Reference dye & {$[102]$} \\
\hline $\mathrm{DiO}$ & 3,3'-dioctadecyloxacarbocyanine perchlorate & Reference dye & {$[101]$} \\
\hline Oregon Green 488-dextran & & Reference dye & [103] \\
\hline PSMA & poly(styrene-co-maleic anhydride) & Polymer matrix & \\
\hline $\mathrm{P}(\mathrm{VDC}-\mathrm{co}-\mathrm{AN})$ & poly(vinylidene chloride-co-acrylonitrile) & Polymer matrix & \\
\hline PAN & poly(acrylonitrile) & Polymer matrix & \\
\hline Eudragit RL 100 & $\begin{array}{l}\text { poly-(ethylacrylate-co-methylmethacrylate-co- } \\
\text { trimethyl-aminoethyl methacrylate) }\end{array}$ & Polymer matrix & \\
\hline PVP & poly(vinylpyrrolidone) & Polymer matrix & \\
\hline Pluronic $®$ F-127 & $\begin{array}{l}\text { triblock copolymer: hydrophobic center block (polypropylene glycol) } \\
\text { surrounded by two hydrophilic blocks (polyethylen glycol) }\end{array}$ & Polymer matrix & \\
\hline Ormosil & Organically modified silicates & Silicate matrix & \\
\hline TMOS & Tetramethoxysilane & Silicate matrix & \\
\hline DMF & Dimethylformamide & Solvent & \\
\hline THF & Tetrahydrofuran & Solvent & \\
\hline SDS & Sodium dodecyl sulfate & Emulsifier & \\
\hline
\end{tabular}




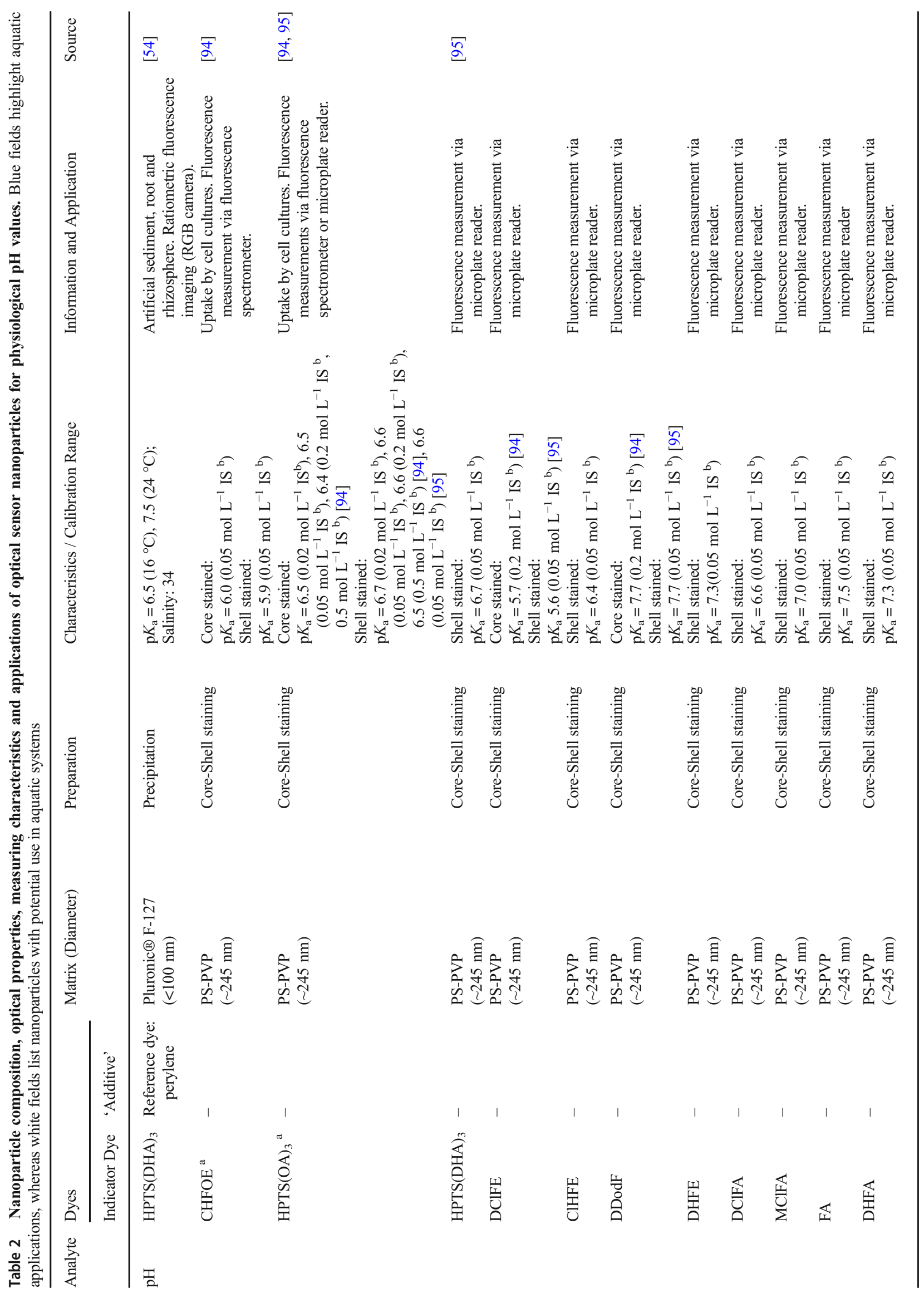


and disadvantages. Examples described in literature are summarized in the supplementary material and aquatic applications are discussed in "Optical sensor particles: current and future applications" section.

Precipitation-based nanoparticle preparation Precipitationbased NP (Fig. 5a) preparation relies on the different solubility of a polymer in two miscible solvents of different polarity. First the polymer is added to a solvent in which it dissolves easily. Subsequently, the polymer solution is poured into a solvent of different polarity (e.g. from an organic solvent into water), where the polymer precipitates, and forms particles in order to minimize the surface area. The analyte-sensitive dye, relevant reference dyes, and additives such as magnetic NPs [88] can be dissolved together with the polymer and are incorporated into the polymer matrix upon precipitation, forming analyte-sensitive NPs [104, 105]. The first solvent, in which the polymer is well soluble, is then removed via evaporation, and the solution can be further concentrated as required [88, 104].

This method has been used to produce $\mathrm{O}_{2}$ sensitive NPs for aquatic applications, such as the production of artificial sediment [53], for spray-coating coral fragments [52], or 3D bioprinting of algae and other cells in hydrogels functionalized with NPs [67] (See "Optical sensor particles: current and future applications" section for more details). The major advantages of this technique are the fast, cheap and easy production of NPs. No expensive, complicated laboratory equipment or excessive chemical knowledge is required and large amounts of NPs can be produced in a very short period of time (hours). Another advantage is the possibility to modify the surface of the polymer NPs. Mistlberger et al. [88] have modified the sensor particle surface: i) Fluorophores such as indicator dyes or fluorescent labels were covalently bound to the carboxyl groups at the NPs surface; ii) The enzyme glucose oxidase (GOX) was linked to the particle surface via amino groups; iii) Stimuli-responsive polymers were polymerized around the core sensor NP to produce e.g. particles that change size upon temperature change; iv) Layer-by-layer deposition of alternating positively and negatively charged polymers.

Microemulsion polymerization A microemulsion is a stable, transparent mixture of two immiscible liquids (such as oil and water), and (co)surfactants in order to e.g. lower the tension of the oil-water interface $[11,106]$. For the polymerization (Fig. 5b), the monomer can be present in either the aquatic or oil phase. Radical polymerization is started by an initiator, resulting in the formation of oligomeric radical chains that become trapped in the lipophilic micelles with increasing chain length. The chains continue to grow as long as monomer is supplied (e.g. from the surrounding solution or from nonnucleated micelles, which collide with the nucleated micelle 


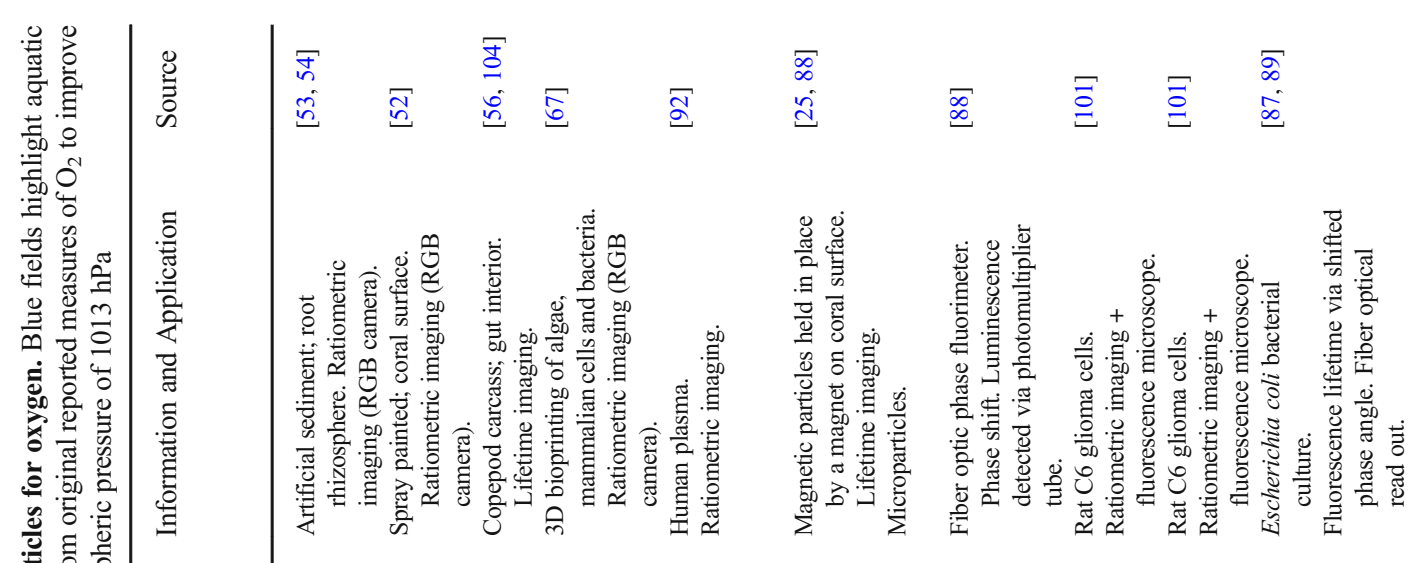

政

ฮิ

害

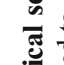




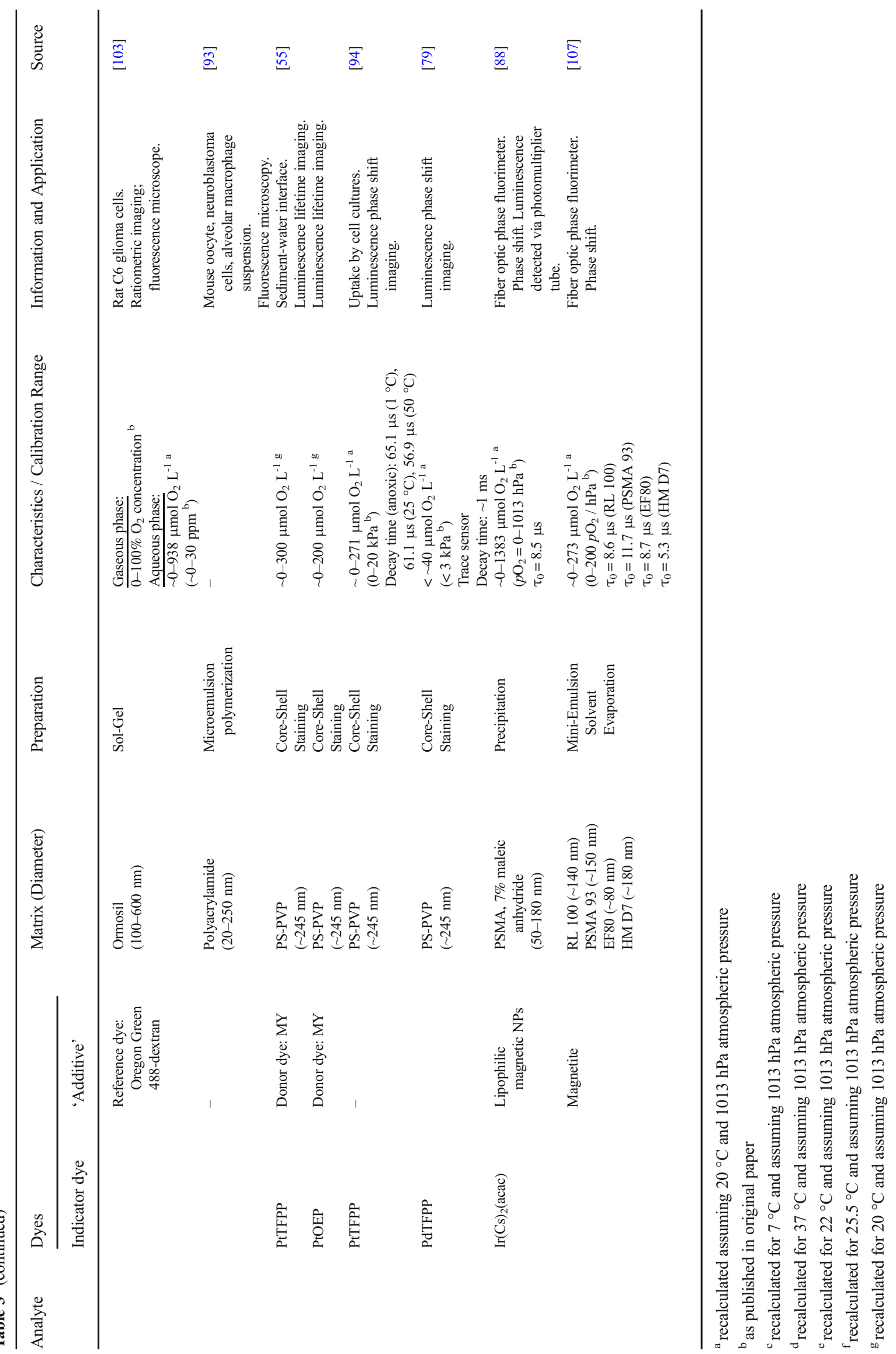


containing the growing polymer chain). The polymerization is terminated by a chain-transfer reaction to a monomer [106]. If the oil phase is dispersed in water $(\mathrm{O} / \mathrm{W})$, it is referred to as direct microemulsion polymerization, while dispersion of the water phase in oil (W/O) is called reversed [11], inverse, or bicontinuous [106] microemulsion polymerization. Emulsion polymerization allows relatively high throughput and is flexible regarding material and solvents, as all immiscible $\mathrm{O} / \mathrm{W}$ and $\mathrm{W} / \mathrm{O}$ combinations can be used [107]. It also produces small NPs with narrow size distributions [106] in high yields [108]. However, it requires emulsifiers and is more complicated and expensive in comparison to e.g. the precipitation technique for sensor NP formation. However, the frequently used emulsifier sodium dodecyl sulfate (SDS) is denaturizing and should be replaced with a more biocompatible emulsifier when making NPs for biological applications [107].

Mini-emulsion solvent evaporation technique Mini-emulsion solvent evaporation (MESE; Fig. 5c) is based on a two-phase system. The polymer, the dye chemistry and relevant additives are dissolved in an organic solvent and mixed with deionized water treated with an emulsifier. The mixture is cooled in an ice bath and sonicated using a high-energy probe sonicator at a certain amplitude for a certain amount of time. After particle formation, the solvent is in equilibrium between the aqueous phase and the organic phase (droplets). The solvent is removed from the aqueous phase by evaporation. Consequently, to maintain equilibrium, the solvent is driven out of the NP into the aqueous phase, reducing the size of the NP. Variations in NP size $(40-200 \mathrm{~nm})$ depend on factors such as viscosity of the organic phase, mechanical shear stress (sonication), solvent evaporation [109], polymer concentration, as well as emulsifier concentration [107]. If suitable emulsifiers are available, both $\mathrm{O} / \mathrm{W}$ as well as $\mathrm{W} / \mathrm{O}$ systems are possible in MESE. The technique is more costly than NP precipitation or spray drying (see below), but very flexible regarding materials and solvents. In comparison to the other NP precipitation techniques, MESE enables the fabrication of larger amounts of optical sensor NPs with a narrow size distribution [107].

Polymer staining A core-shell structured block-copolymer can be used in combination with different solvents in order to stain either the core or the shell of polymer NPs with a lipophilic indicator dye. Borisov et al. [79] described the fabrication of different analyte-sensitive NPs based on swelling and dye diffusion into a polymeric core-shell system. Here the core polymer was hydrophobic polystyrene (PS), while the shell was the highly biocompatible and hydrophilic polymer poly(vinylpyrrolidone) (PVP) [79, 110]. NPs based on this copolymer are easily dispersible in water and show no leaching of indicator dye. Additionally, they can be freeze-dried and 


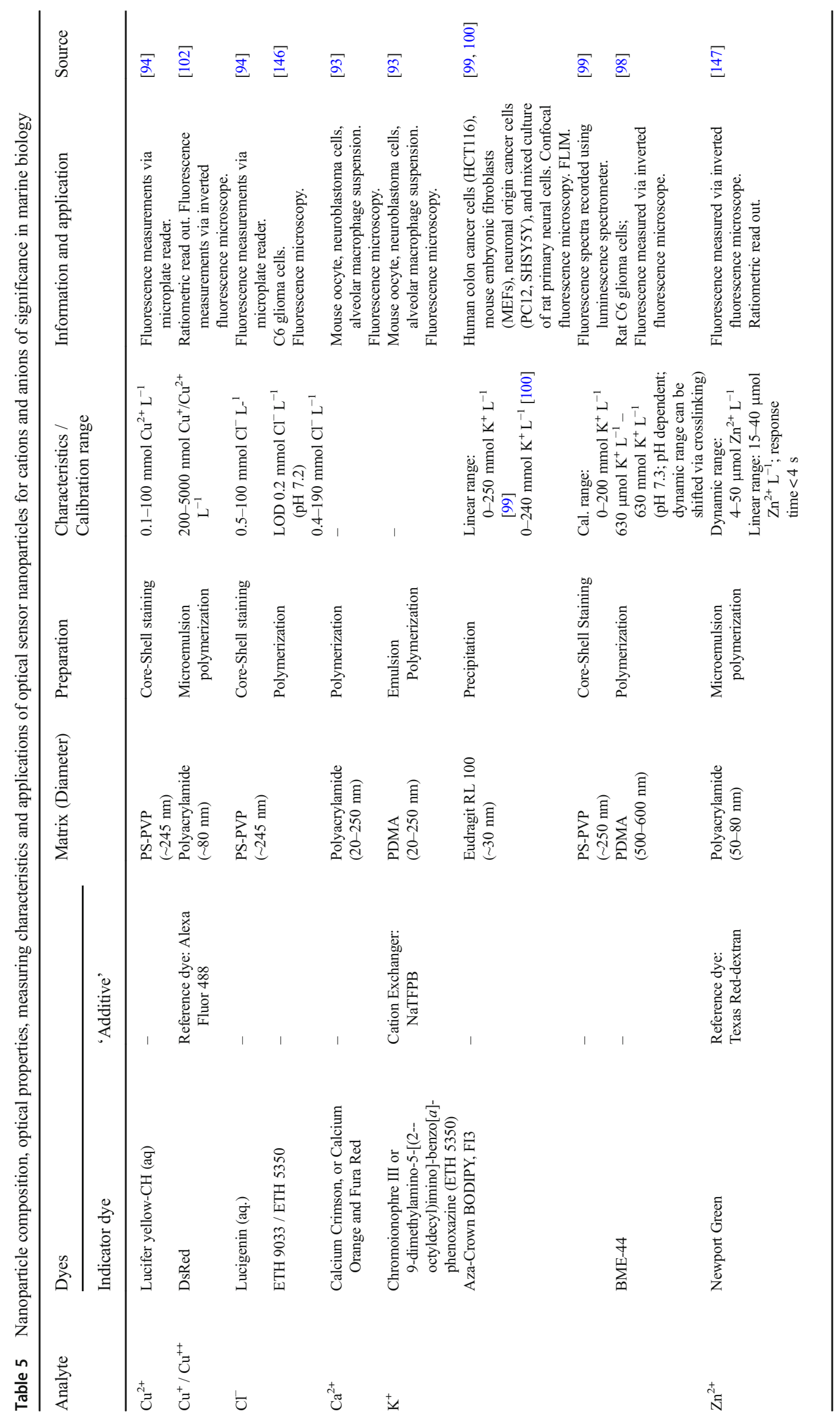




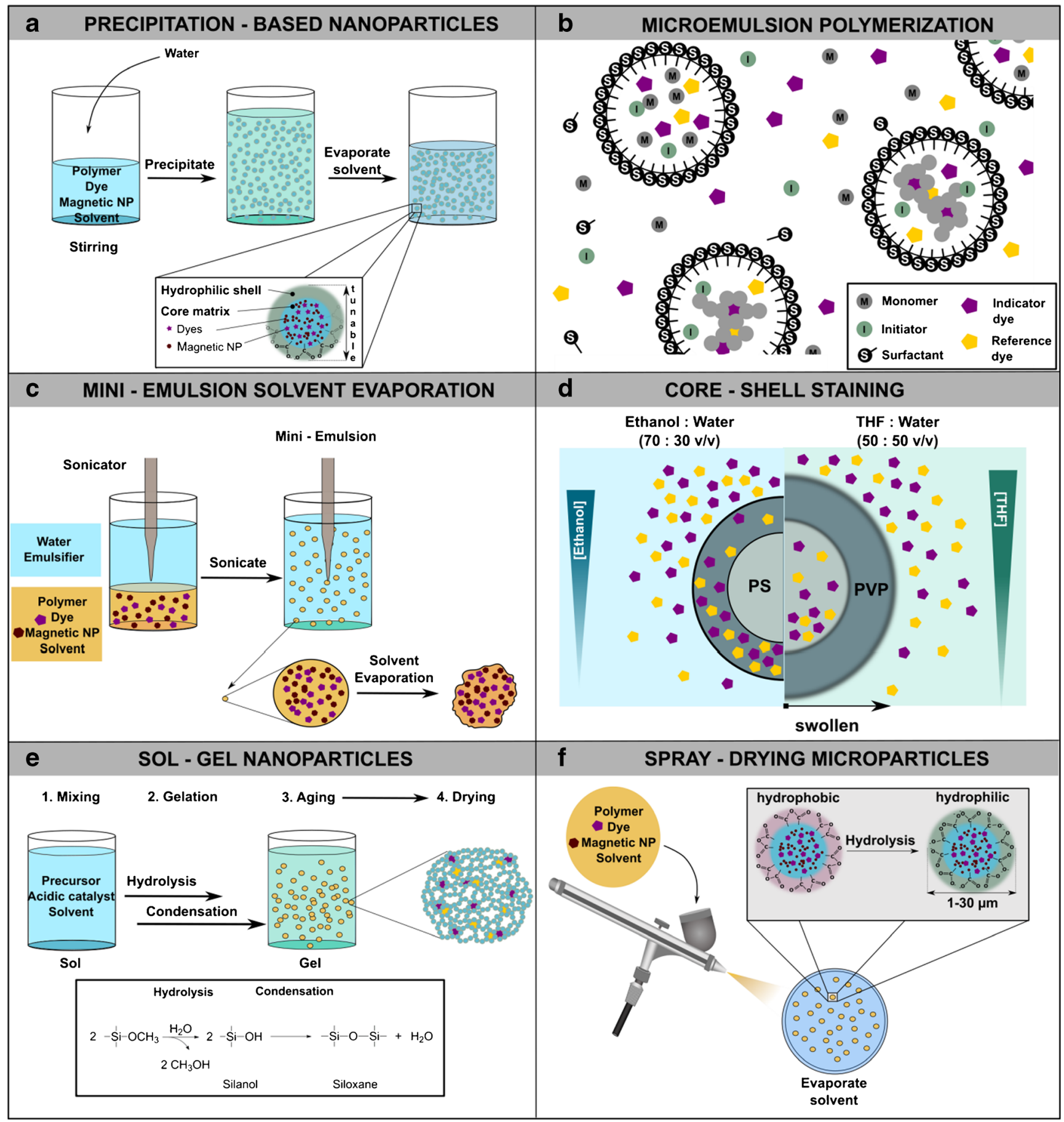

stored for an indefinite amount of time and can simply be redispersed prior to their application. Depending on the used solvents, either the core or the shell can be stained with a lipophilic dye (Fig. 5d). A THF:water mix (50:50 v/v) is used to stain the core, while an ethanol:water mix $(70: 30 \mathrm{v} / \mathrm{v})$ is employed for staining the shell [94]. It is recommended to incorporate $\mathrm{O}_{2}$ and temperature sensitive dyes in the core in order to shield them from potential other quenchers (e.g. halides) and minimize potential leaching of singlet oxygen formed during the measurement, while $\mathrm{pH}$, chloride and copper ion-sensitive dyes should be incorporated into the shell to allow sufficient permeation from the surrounding medium [94]. Many different indicator dyes for $\mathrm{O}_{2}$ [79] and $\mathrm{pH}$ values[95] have been incorporated into core-shell NPs. The unstained nanoparticles are commercially available. The fabrication of these stained core-shell NPs is overall very easy and can be done in large quantities. They do not aggregate and are apparently non-toxic [94, 95]. 
4 Fig. 5 Preparation of optical sensor nanoparticles (a) Precipitationbased nanoparticle preparation. The water insoluble polymer, the indicator dye, a possible reference dye, and other additives (e.g. magnetite) are dissolved in a water miscible organic solvent. Upon addition of water, the polymer forms spheres precipitating from the solution. Subsequently, the solvent is removed and the solution can be further concentrated to the required nanoparticle concentration. b Microemulsion polymerization takes place in a two-phase system (e.g. oil and water). The initiator starts the radical polymerization in the aqueous phase. With increasing chain length, the oligomeric radicals are better soluble in the oil - droplets and are trapped in the micelles. Scheme adapted from Bonham et al. [108]. c Mini-emulsion solvent evaporation technique used for NP preparation. Two immiscible phases, an organic phase containing the polymer, dye and magnetic nanoparticles, and a water phase with the emulsifier are emulsified via sonication, forming nanodroplets. The solvent is in equilibrium in the water phase and the droplets. Upon evaporation of the solvent, the nanoparticles shrink to their final size. d Controlled staining of core-shell nanoparticles. Exemplified for poly(styrene-co-vinylpyrrolidone) (PS-PVP) NPs. Left: The NP shell is stained by dispersing the block copolymer, and dissolving the lipophilic dyes in an ethanol:water mix $(70: 30 \mathrm{v} / \mathrm{v})$. The ethanol concentration is lowered, forcing the dyes into the hydrophilic shell. No swelling in ethanol:water mixture is observed in comparison to just water. Right: In order to stain the core, the block copolymer is dispersed in a THF:water mix (50:50 v/v). The dyes are dissolved in THF and added dropwise to the emulsion. Removing the THF forces the lipophilic dyes into the lipophilic core. Swelling of the NP is observed. e Sol - Gel nanoparticles. Step 1 Mixing: the precursor (e.g. $\left.\mathrm{Si}\left(\mathrm{OCH}_{3}\right)_{4}\right)$, the acidic catalyst, and the indicator dye are mixed in a solvent. 2. Gelation: the precursor hydrolyses to silanol and subsequently condenses to siloxane. 3. Aging: the polycondensation reaction continues. 4. Drying: the solvents are removed leaving the porous sensor NP. f Spray-drying method to produce optical microparticles. A cocktail containing the dissolved polymer, dye and magnetic NPs is sprayed in a beaker. The solvent is evaporated and the hydrophobic microparticles hydrolyze, resulting in hydrophilic microparticles $(1-30 \mu \mathrm{m})$

Sol-gel materials Hydrolysis and poly-condensation of organometallic compounds such as silicon alkoxides at low temperatures result in the formation of a porous, transparent glass-like structure referred to as sol-gel (Fig. 5e). The size of the pores in sol-gel can be controlled by the choice and amount of used precursor as well as the conditions during the reaction. The solgel process takes place in 4 steps [111]: 1) mixing the metal alkoxide precursor (most commonly used precursor [112]) with water, an acidic or basic catalyst and a solvent to form a solution (=sol formation) [111]. Basic catalysis of the condensation reaction predominantly results in small NPs, whereas acidic catalysis results in branching, linear shapes [112]. 2) Gelation: the precursor (e.g. $\left.\mathrm{Si}\left(\mathrm{OCH}_{3}\right)_{4}\right)$ hydrolyses, forming silanol groups, which subsequently form siloxane polymers upon condensation. In other words bridging bonds are formed from reactive sites [112]. This siloxane and silanol polycondensate forms amorphous, gel$\mathrm{SiO}_{2}$ clusters (=gel, vial sol-gel transition) with the silanol groups located at the surface of the gel. 3) Aging: in this step the polycondensation reactions continue, while the gel is kept in liquid.

4) Drying: the solvents are removed from the porous gel [111].

Indicator dyes can be added either during the sol or the gel formation, and it is also possible to introduce magnetic NPs, resulting in magnetic OSPs [89]. Production of sol-gel materials is environmentally friendly by avoiding organic solvents or surfactants, which are frequently used in other OSP preparation techniques [113]. Their 'soft' chemical production, i.e., preparation at room temperature and ambient air pressure [3, 114], and their porous, easily modifiable structure, which is optically transparent, chemically inert and thermally stable [3, $114,115]$ is a great advantage of sol-gel materials. As the luminophore/indicator dye is only physically entrapped in the sol-gel, its spectral properties remain close to unchanged upon OSP preparation. Physical entrapment can easily be optimized in this system as the pore-size is tunable by the reaction conditions $[90,114]$ ensuring that the luminophore is entrapped, while the analyte of interest is still able to diffuse into the particle [114]. Sol-Gel OSPs are biocompatible and non-toxic [90], making them suitable candidates for applications in biological systems.

The particle sizes and shape is influenced by many factors during the production. It is described in literature that the use of metal alkoxides allows the fabrication of particle sizes in the range of $20 \mathrm{~nm}-1 \mu \mathrm{m}$ [116]. The amount of base catalyst, as well as the chosen co-solvent greatly influence the final particles size [113]. Growth of round particles takes place in sols when most - OR groups have been hydrolyzed. Particles start growing as result of condensation of the formed $-\mathrm{OH}$ groups. Then, so called Oswald ripening can takes place, where larger particles get bigger while smaller particles disappear. Size can be controlled for instance by avoiding agglomeration to larger particles via e.g. centrifugal deposition of the formed particles, or volatilization of the solvent $[112,116]$.

Spray drying Here, a polymer is dissolved together with the indicator dye and eventually magnetic nanoparticles in an organic solvent and sprayed into a heated beaker using an airbrush (Fig. 5f). Spray drying results in hollow, porous and fast responding sensor microparticles $(1-30 \mu \mathrm{m})$ [107]. The particles are dispersed in ethanol, hydrolyzed in an ultrasonic bath and washed with water [117]. Spray drying-based fabrication results in a very homogenous distribution of the dispersed microparticles, due to the fast evaporation of the solvent, which is an advantage in comparison to precipitation or polymerization techniques [118]. Overall, this is a very easy and user-friendly technique. It allows the use of various polymers, solvents and additives, relies on low-cost equipment and does not need e.g. emulsifiers which would have to be removed [117, 118].

\section{Optical sensor particles: current and future applications}

Optical sensor particles are ideal micro-environmental analysis tools when measuring spatio-temporal dynamics of chemical parameters over heterogeneous surfaces. Such samples 
include the root-systems (rhizosphere) of plants [53, 54], coral surfaces [52], biofilms and other abiotic and biotic matrices with complex structures. OSPs enable 2D chemical imaging without close contact to a sensor foil, and thus overcome many of the limitations of more commonly used planar optodes and microsensor-based techniques. In addition, optical sensor NPs can be incorporated into transparent media, such as artificial sediment [53, 54], alginate beads [119] or in 3D bioprinted constructs [67], thus enabling precise alignment and visual assessment of the structures of the sample with the chemical images. In the following, we give an overview of typical and future applications of optical sensor particles for imaging chemical parameters in aquatic systems.

\section{Imaging of $\mathrm{O}_{2}$ in samples with complex surface topography}

\section{Coral tissue surface spray-painted with optical sensor nanoparticles}

$\mathrm{O}_{2}$ sensitive optical sensor NPs have been used to map the tissue surface $\mathrm{O}_{2}$ concentration over coral fragments (Fig. 6; [52]). This NP-based approach allowed for precise assessment of coral $\mathrm{O}_{2}$ production and consumption at high spatiotemporal resolution $(\sim 0.1 \mathrm{~mm}$ resolution; $<10 \mathrm{~s}$ response time) over areas ranging from several $\mathrm{cm}^{2}$ of coral tissue to individual
$<1-2 \mathrm{~mm}$ wide coral polyps. The $\mathrm{O}_{2}$-sensitive sensor NPs were produced via precipitation using PtTFPP (Fig. S1) as indicator dye and MY as reference dye in a PSMA polymer matrix. They were spray-painted onto small coral fragments using a conventional airbrush, which enabled covering the whole coral tissue surface with a thin and even distribution of sensor NPs [52]. Net photosynthetic $\mathrm{O}_{2}$ production by the coral microalgal symbionts in the light, and the combined respiration of symbionts and coral animal tissue in darkness confirmed that the thin layer of optical sensor NPs did not significantly compromise coral health during the $\mathrm{O}_{2}$ imaging [52]. Chemical $\mathrm{O}_{2}$ images were recorded using a ratiometric luminescence imaging system [31], employing a simple SLR camera equipped with a macro-objective and a long-pass filter (455 nm), while the sensor NPs were excited by a $405 \mathrm{~nm}$ LED combined with a bandpass filter. One of the major advances of this technique is that the optical sensor NPs do not create a diffusion barrier causing smearing effects in the $\mathrm{O}_{2}$ images, as can be seen when pressing surfaces up against a planar optode (e.g. Meysman et al. [120]). Drawbacks of the method are, however, that the sensor NPs are limited to controlled laboratory measurements on corals, or other biological samples, without fluorescent host pigments (e.g., green fluorescent protein (GFP-like pigments in corals [121]), as this can lead to an increased signal in the green channel and thus false $\mathrm{O}_{2}$ readings [52]. However, this can be alleviated by using
Fig. 6 A coral fragment spraypainted with $\mathrm{O}_{2}$ sensitive nanoparticles. a Shows the original fragment of the coral Porites lobata. The site of fracture, damaged tissue and out of focus areas are highlighted. b The coral fragment with sensor NPs that were excited with $405 \mathrm{~nm}$ light. c Color-coded image showing $\mathrm{O}_{2}$ hotspots and depletion after $30 \mathrm{~min}$ in darkness. Reprinted from Sensors and Actuators B: Chemical, 237, Koren K., Jakobsen S. L., Kühl M., In-vivo imaging of $\mathrm{O}_{2}$ dynamics on coral surfaces spraypainted with sensor nanoparticles, 1095-1101, ( ) 2016 Elsevier B.V. (2016), with permission from Elsevier [53]
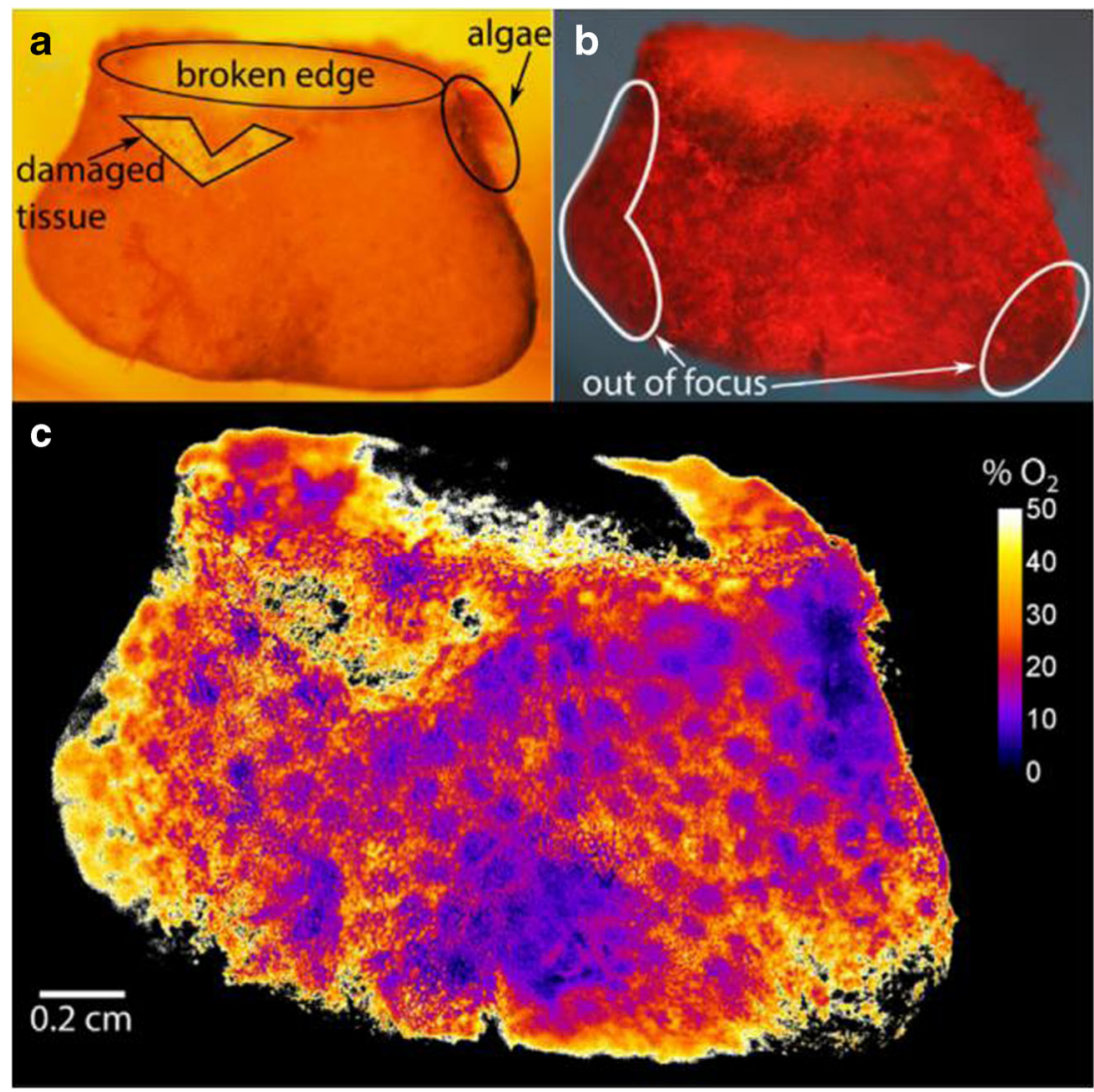
luminescence lifetime-based imaging for readout, which is not sensitive to such sample background fluorescence (see "Magnetic optical sensor particles" section). The ratiometric imaging approach described by Koren et al. [52], enabled linking different tissue types (e.g., polyp tissue versus connective coenosarc tissue between individual coral polyps) as well as healthy in comparison to stressed tissue areas, with the heterogeneity in the $\mathrm{O}_{2}$ concentration and dynamics over the whole coral tissue surface. While this study used $\mathrm{O}_{2}$-sensitive NPs that were passively adhering to the coral tissue surface, even under flow, active immobilization of such sensor NPs is possible either by functionalizing the NP surface for active binding to tissue surfaces or by using magnetized particles as outlined in the following section.

\section{Magnetic optical sensor particles}

Magnetic optical $\mathrm{O}_{2}$ sensor MPs $(\sim 80-100 \mu \mathrm{m})$ were developed to visualize surface $\mathrm{O}_{2}$ concentrations and dynamics in corals with fluorescent host pigments [25]. Here, the $\mathrm{O}_{2}$ sensitive sensor microparticles contained the NIR-emitting luminophore PtTPTBPF (Fig. S1) and were immobilized on the coral polyp surface via a strong magnetic field (Fig. 7). A luminescence lifetime imaging system, consisting of a sensitive fast gate-able camera was used for data acquisition [59, 60]. The utilization of a red light excitable, NIR-emitting $\mathrm{O}_{2}$ indicator dye has several advantages. Red light induces lower excitation light stress than under UV or blue excitation, which can trigger biological responses. The spectral characteristics of the sensor enable combining the sensor particles with variable chlorophyll fluorescence imaging, GFP-reporters or DNA stains, e.g. allowing for quantification of coral host pigments, without interference from the sensor particle readout
[25]. The magnetic sensor particles were used to map the spatiotemporal dynamics of the coral polyp $\mathrm{O}_{2}$ microenvironment as a function of coral host pigments and light intensities. However, much less efficient areal coverage than in the NPbased study of Koren et al. [52] was achieved, mainly due to excessive mucus formation sloughing off sensor MPs over time. Nevertheless, the ability to superimpose sensor particle-based chemical $\mathrm{O}_{2}$ images onto structural coral images enables novel experimental studies linking the distribution and dynamics of photosynthesis and respiration to the coral surface topography and particular tissue types with different pigmentation and density of symbionts and microbes. Similar studies can also be realized on other aquatic systems such as e.g. biofilms (M. Kühl unpublished results).

\section{Measurement of internal $\mathrm{O}_{2}$ concentration dynamics and distributions}

\section{Marine snow: copepod carcasses as microbial hotspots}

Copepod carcasses have recently been identified as microbial hotspots for pelagic denitrification via a novel application of sensor microparticles for internal $\mathrm{O}_{2}$ imaging, in combination with ${ }^{15} \mathrm{~N}$ tracer experiments, and microbial sampling for nitrite reductase gene expression [56]. Sinking and decomposing carcasses of copepods act as anoxic microhabitats facilitating anaerobic microbial activity in otherwise oxic water-columns. $\mathrm{O}_{2}$ sensitive sensor MPs (diameter 2-12 $\mu \mathrm{m}$ ) were made of the $\mathrm{O}_{2}$ indicator PtTFPP (Fig. S1) embedded in PS-MA together with the antenna dye MY [56]. The sensor microparticles were mixed with the cryptophyte Rhodomonas salina (ratio of $\sim 1: 20$ ) and fed to the investigated $C$. finmarchicus copepods. The

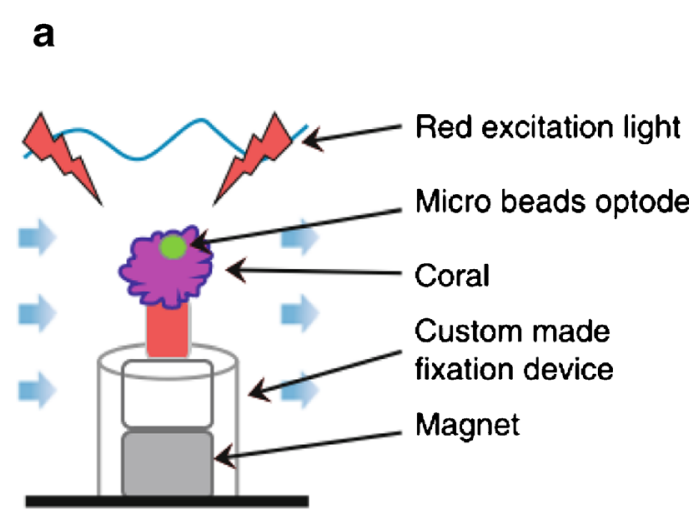

Fig. 7 Application of magnetic sensor microparticles for mapping $\mathrm{O}_{2}$ dynamics. a Schematic drawing of a coral fragment, coated with magnetic, $\mathrm{O}_{2}$-sensitive microparticles held in place by a strong magnet. b Image of a polyp of the coral Caulastrea furcata in air saturated water (205 $\mu \mathrm{mol} \mathrm{O}_{2} \mathrm{~L}^{-1}$ ). c Luminescence intensity image of the polyp. d Distribution of $\mathrm{O}_{2}$ concentraion over the coral tissue upon irradiation with visible light $(400-700 \mathrm{~nm})$ at a photon irradiance of $63 \mu \mathrm{mol}$

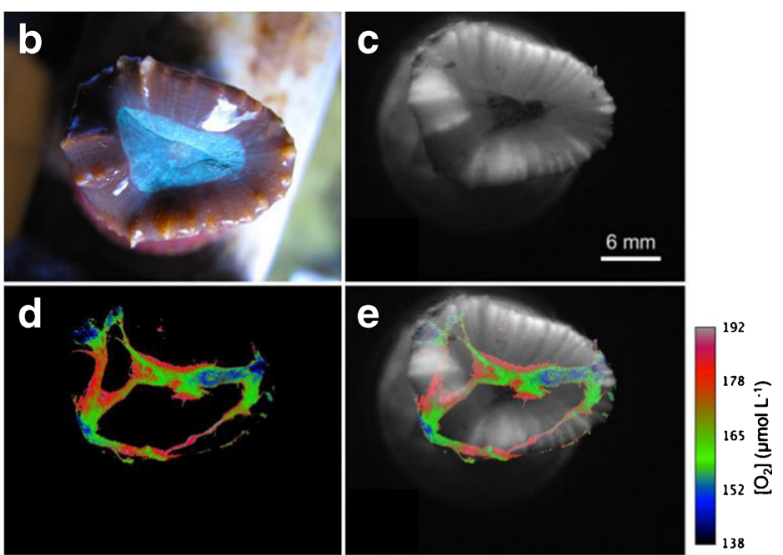

photons $\mathrm{m}^{-2} \mathrm{~s}^{-1}$. e Overlay of $\mathbf{c}$ and $\mathbf{d}$. Reproduced from [38]. Reprinted by permission from [Springer Nature Customer Service Centre $\mathrm{GmbH}$ ]: [Springer] [Marine Biology] [26] (Imaging of surface $\mathrm{O}_{2}$ dynamics in corals with magnetic micro optode particles, FabriciusDyg J., Mistlberger G., Staal M., Borisov S. M., Klimant I., Kühl M.), [@Springer-Verlag 2012] (2012) 
microparticles were imaged with a luminescent lifetime imaging approach, where a fast gate-able 12-bit CCD camera combined with a $590 \mathrm{~nm}$ longpass filter [59] was used to record the luminescent lifetime of the sensor MPs inside the gut of the transparent copepod carcasses [56]. A deep blue LED equipped with a $470 \mathrm{~nm}$ shortpass filter was used as excitation light. [60]. The carcasses of the copepod Calanus finmarchicus showed an anoxic interior microenvironment, even at $100 \%$ air saturation in the ambient water-column, and the internal anoxic region expanded with decreasing external $\mathrm{O}_{2}$ levels (Fig. 8). Hence, optical sensor (micro)particles also enable internal $\mathrm{O}_{2}$ measurements of transparent/semi-transparent tissues and/or media.

\section{Transparent media with incorporated optical sensor nanoparticles}

Sensor NPs can also be incorporated in various semitransparent matrices that can be used for embedding cells, tissues or whole organisms. This has e.g. enabled the imaging of $\mathrm{O}_{2}$ dynamics around microcolonies of pathogenic bacteria in alginate beads containing $\mathrm{O}_{2} \mathrm{NPs}$ [119]. A similar approach can also be used at larger scale to visualize and quantify $\mathrm{O}_{2}$ and $\mathrm{pH}$ microenvironments around aquatic plants as detailed in the following sections.

\section{Rhizosphere $\mathrm{O}_{2}$ microenvironment and dynamics}

Optical sensor NPs have been successfully incorporated into reduced, transparent artificial sediment to visualize $\mathrm{O}_{2}$ concentrations and dynamics around rhizomes and roots of seagrasses [53, 54]. The transparent artificial sediment was functionalized via incorporation of optical $\mathrm{O}_{2}$ sensor NPs consisting of PtTFPP (Fig. S1, Table 1) and MY (Table 1) in PSMA (Table 1) into a pH-buffered, deoxygenated sulfidic agar matrix [53]. A ratiometric luminescence imaging approach was chosen, using a SLR camera system and blue LED excitation [31, 52]. The functionalized artificial sediment was used for real-time mapping of the $\mathrm{O}_{2}$ distribution and dynamics in the entire seagrass rhizosphere upon changing light conditions and water-column $\mathrm{O}_{2}$ concentrations surrounding the plant leaves (Fig. 9; [53]). Seagrass growth and photosynthetic activity was not compromised when immobilizing the belowground tissues into the functionalized, reduced artificial sediment as the cultured seagrasses showed similar growth rates and quantum yields of photosystem II (PSII) (i.e., a measure of the plants photosynthetic activity [122]) as in healthy natural seagrass populations. Radial $\mathrm{O}_{2}$ loss from the belowground tissue of seagrasses, especially the root/shoot junctions and root-tips, was highest during illumination of the leaf canopy
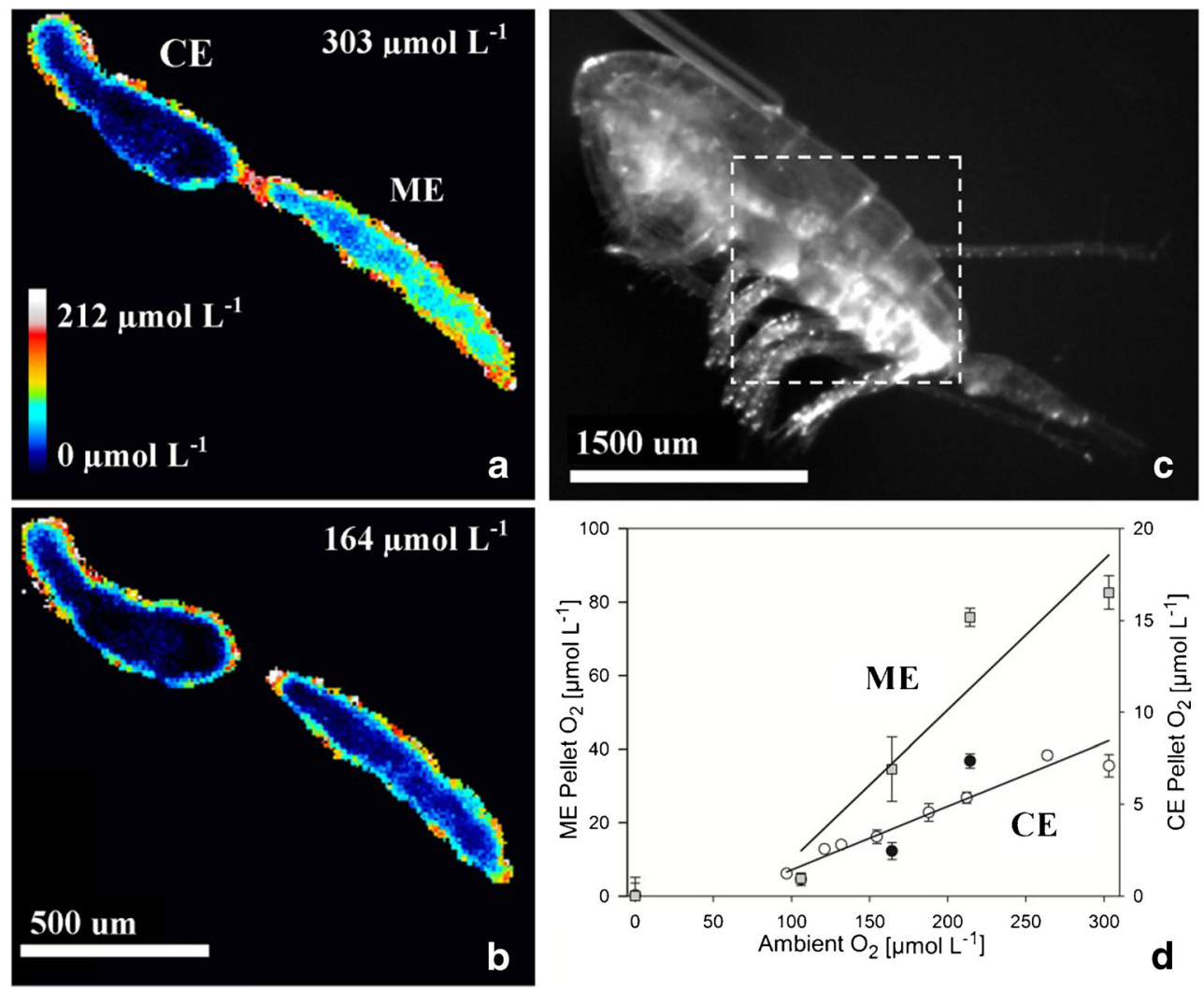

Fig. 8 Internal $\mathrm{O}_{2}$ dynamics measured in the gut of a dead copepod. a) $\mathrm{O}_{2}$ concentrations in the gut interior at ambient $\mathrm{O}_{2}$ concentration, and $\mathbf{b}$ ) at a concentration of $164 \mu \mathrm{mol} \mathrm{O} \mathrm{L}^{-1}$ in the surrounding water medium. c) Image of the carcass fixed on a metal wire glued to the head region. The white, dashed square shows the region of interest depicted in $\mathbf{a}$ and $\mathbf{b}$. d)

Internal $\mathrm{O}_{2}$ concentrations found in different carcasses. Reproduced from Glud et al. [6]; @2015 The Authors Limnology and Oceanography published by Wiley Periodicals, Inc. on behalf of Association for the Sciences of Limnology and Oceanography 

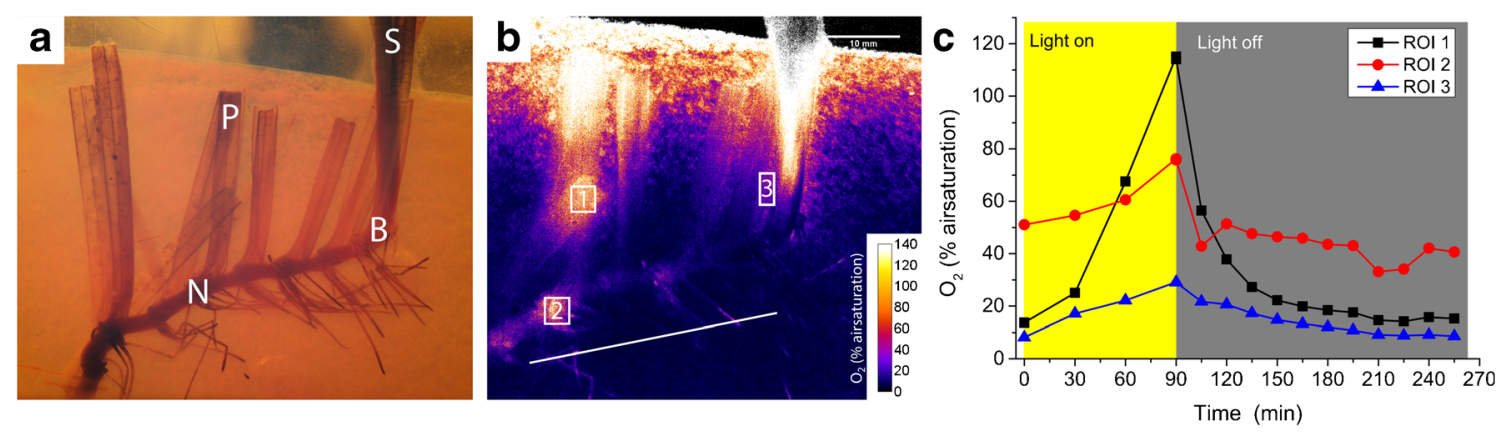

Fig. 9 Optical $\mathrm{O}_{2}$-sensitive NP incorporated in an agar matrix resembling artificial sediment to visualize chemical gradients in the rhizosphere of seagrasses. a Image of the seagrass Zostera muelleri within the artificial sediment. b Color-coded image showing the $\mathrm{O}_{2}$ distribution around the roots and leaves after irradiation for $90 \mathrm{~min}$ at a photon irradiance (400$700 \mathrm{~nm}$ ) of $500 \mu \mathrm{mol}$ photons $\mathrm{m}^{-2} \mathrm{~s}^{-1}$. c Time course of $\mathrm{O}_{2}$ concentration in three areas of interest (white squares in panel b) over a light - dark

and lowest during darkness in a deoxygenated water-column (Fig. 9). This demonstrated the strong dependence of seagrasses on passive diffusion of $\mathrm{O}_{2}$ into their leaves during darkness to sustain aerobic metabolism in distal roots and maintain seagrassgenerated rhizospheric oxic microzones; [123-125]. In comparison to partial mapping with planar $\mathrm{O}_{2}$ optodes and microsensorbased point measurements, the artificial sediment functionalized with sensor NPs enables chemical imaging of the whole rhizosphere, which is a significant methodological advancement for microenvironmental studies of plant rhizospheres [53].

\section{Rhizosphere $\mathrm{pH}$ microenvironment and dynamics}

Artificial sediment functionalized via $\mathrm{pH}$ sensitive optical sensor NPs were developed to study the dynamics and exposure experiment. Reprinted (adapted) with permission from Environmental Science \& Technology, 49, Koren K, Brodersen KE, Jakobsen SL, Kühl M, Optical Sensor Nanoparticles in Artificial Sediments-A New Tool to Visualize $\mathrm{O}_{2}$ Dynamics around the Rhizome and Roots of Seagrasses, 2286-2292, (C) 2015 American Chemical Society [54]

heterogeneity of $\mathrm{pH}$ values in plant rhizospheres [54]. Here, a ratiometric luminescence imaging approach was chosen using a multichip $405 \mathrm{~nm}$ LED combined with a bandpass filter as excitation light and a SLR camera combined with a macro-objective lens and a $455 \mathrm{~nm}$ longpass filter for imaging recordings [54]. The optical $\mathrm{pH}$ sensor NPs consisted of a reference dye, perylene, and a lipophilic indicator dye,

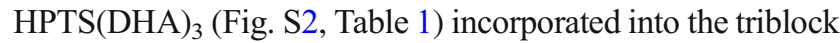
copolymer Pluronic ${ }^{\circledR}$ F-127. The final sensor NP concentration in the reduced agar matrix was $\sim 7 \%(v / v)[54]$ and enabled first whole rhizosphere imaging of the $\mathrm{pH}$ dynamics around seagrass tissue upon changing environmental conditions such as light/dark conditions and temperature increases. Pronounced micro-heterogeneity was observed within the seagrass rhizosphere (Fig. 10), with distinct low and high

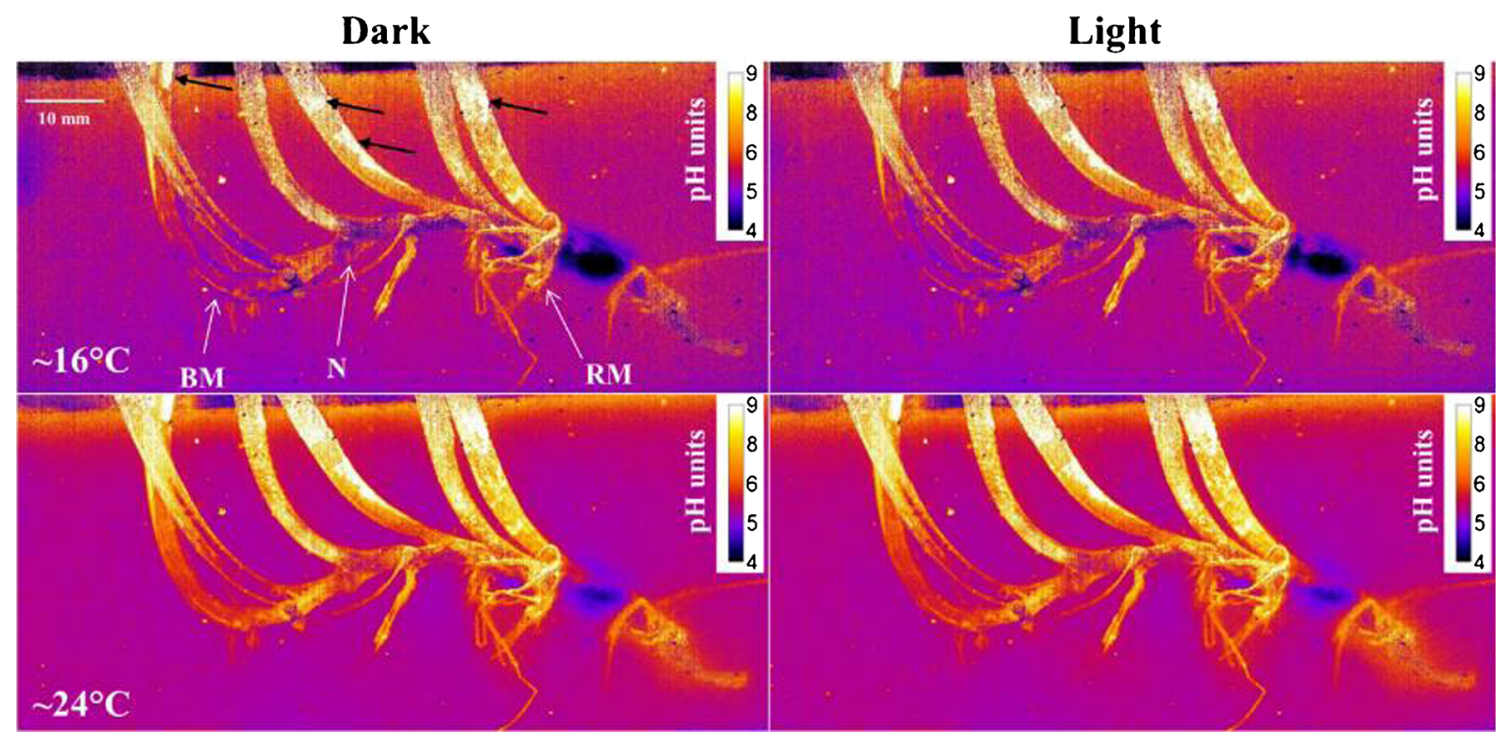

Fig. $10 \mathrm{pH}$ dynamics around the roots (and leaves) of the seagrass Zostera marina $L$. visualized by $\mathrm{pH}$ sensitive nanoparticles incorporated in an artificial sediment made of agar. The color-coded images were acquired at different temperatures (top $\sim 16{ }^{\circ} \mathrm{C}$, bottom $\sim 24{ }^{\circ} \mathrm{C}$ ) and dark (left) - light (right) transitions. Incident light was $500 \mu \mathrm{mol}$ photons $\mathrm{m}^{-2} \mathrm{~s}^{-1}$. BM = basal leaf meristem, $\mathrm{N}=$ nodium, $\mathrm{RM}=$ mature zone of the root bundle. Reproduced from [55]; ( 2016 John Wiley \& Sons Ltd., Plant, Cell and Environment, 39,1619-1630 
$\mathrm{pH}$ microenvironments around the belowground seagrass tissue as compared to the bulk sediment $\mathrm{pH}$. The low $\mathrm{pH}$ microenvironments correlated with the plant-driven oxic sediment microenvironments (see Fig. 9) as a result of local sulphide oxidation [54]. These belowground oxic microenvironments are very important for the plants as they function as "oxic microshields" that protect the plants from potentially toxic sulphide intrusion (by detoxifying the immediate rhizosphere [123]) and furthermore stimulate microbial oxidation of toxic hydrogen sulphide in the seagrass rhizosphere [126]. Moreover, the acidification of particular rhizosphere microenvironments documented with NP-based imaging (Fig. 10) have demonstrated phosphorous solubilisation in carbonate-rich tropical sediments as a result of protolytic dissolution of carbonates [45].

\section{D bioprinting with bioinks functionalized with sensor nanoparticles}

Besides simple embedding of sensor nanoparticles in hydrogel matrices surrounding the sample as outlined above, it was recently demonstrated that sensor NPs can be incorporated into biocompatible printing materials (bioinks) utilized for 3D bioprinting of constructs containing living cells [67]. The functionalized bioink consisted of $\mathrm{O}_{2}$-sensitive NPs using a PtTFPP indicator dye (Fig. S1, Table 1) and an inert fluorescent coumarin

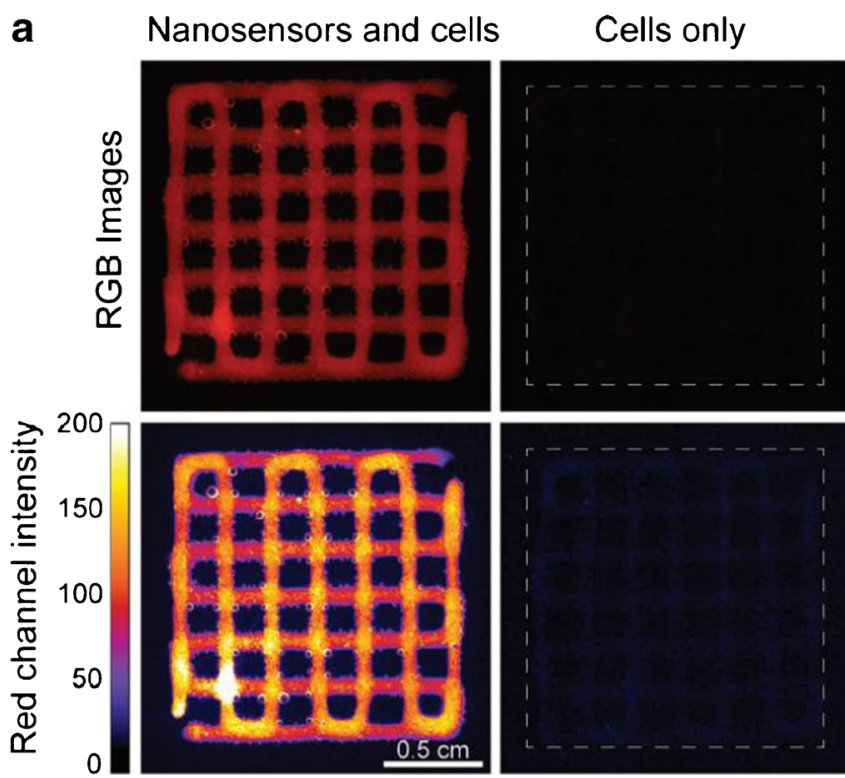

Fig. 11 3D bioprinting of microalgae (Chlorella sorokiniana) and human stem cells in a hydrogel functionalized with $\mathrm{O}_{2}$-sensitive NPs. a Upper panel show the RGB image of the nanosensors + microalgae (left) or just microalgae (right), whereas the lower panel shows the red channel intensity from the sensor luminescence + microalgae (left) and the auto fluorescence
$\left(\mathrm{Bu}_{3} \mathrm{Coum}\right)$ as reference dye in a PSMA matrix, which were homogenously dispersed into an alginate/methylcellulose hydrogel mixture for bioprinting [67]. Such functionalization of bioinks via sensor NPs enabled dynamic $\mathrm{O}_{2}$ imaging of microalgal photosynthesis and respiration in intact $3 \mathrm{D}$ structures without significant interference from microalgal autofluorescence (Fig. 11). Microalgae viability in the 3D printed constructs with sensor NPs was confirmed by variable PAM chlorophyll fluorescence imaging [67, 127].

Using bioink containing sensor NPs allows for rapid evaluation of metabolic activity, and e.g. species interactions within complex structural matrices resembling natural systems (biofilms, corals and other surface-associated microbial communities and symbioses) in response to changing external incubation conditions [67]. Such combination of $3 \mathrm{D}$ bioprinting with chemical imaging is a powerful new tool for microenvironmental analysis in many basic and applied research disciplines, e.g. for describing cellular interactions during formation and development of artificial tissues and biofilms. In addition, by mapping $\mathrm{O}_{2}$ distributions and dynamics in $3 \mathrm{D}$ bioprinted constructs it is now possible to optimize scaffold designs for construction of artificial photosynthetic biofilms or corals with optimal light harvesting capacity and photosynthetic quantum yields, or other constructs that enable efficient growth of different cell types in close proximity [67].

b

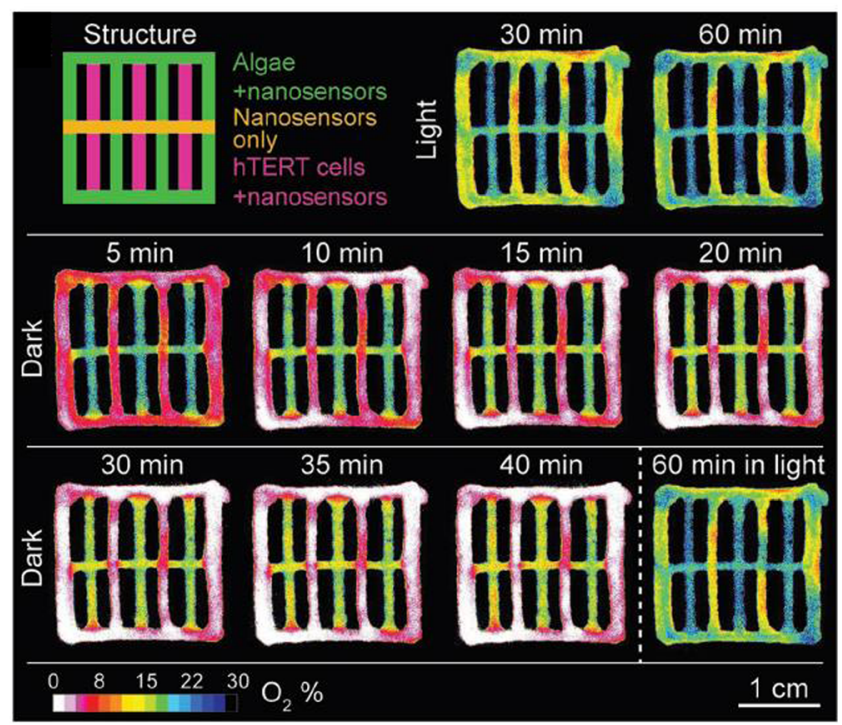

of the microalgae (right). $\mathbf{b}$ Schematic of the different scaffold layers and color-coded images of $\mathrm{O}_{2}$ dynamics in the scaffold after 30 and $60 \mathrm{~min}$ in light (under a photon irradiance of $450 \mu \mathrm{mol}$ photons $\mathrm{m}^{-2} \mathrm{~s}^{-1}$ ), and over time in 5 min intervals after subsequent darkening. Reproduced from [68]; (c) 2018 WILEY-VCH Verlag GmbH \& Co. KGaA, Weinheim 


\section{Measurements at the water-sediment interface}

Sensor NPs (PtTFPP, [Fig. S1; Table 1] and MY [Table 1] in a PS-PVP matrix, diameter $<500 \mathrm{~nm}$ ) have also been used to study the $\mathrm{O}_{2}$ distribution and dynamics around burrows of the larvae of the water insect Chironomus plumosus during active ventilation of their burrows in the sediment [55]. For this, sensor NPs were dispersed in the overlaying water of the burrow and were illuminated with a planar laser light sheet technique. Planar optodes normally restrict water movement at the foil surface and thus affects the $\mathrm{O}_{2}$ concentration distributions across the water/ sediment interface. By applying the laser light sheet technique in combination with a lifetime imaging approach and sensor NPs in the overlaying water for imaging: i) the water movement at the water/sediment interface was not restricted, ii) the signal recordings were independent of the luminescent sensor dye concentrations, and iii) sorption of the sensor dye to sediment particles was limited. This novel imaging technique thus enabled imaging the $\mathrm{O}_{2}$ dynamics at the water-sediment interface under complex flow conditions and allowed first measurements of the ejection of $\mathrm{O}_{2^{-}}$ depleted water plumes from the burrow outlets (Fig. 12) [55].

\section{Conclusion, current challenges and future prospective}

There is tremendous potential for employing optical sensor NPs to study chemical microenvironments in aquatic systems.
They can unravel how changing environmental conditions and community structure affects chemical microenvironments, solute distribution and dynamics at high spatiotemporal resolution with minimal interference. Currently, mainly optical $\mathrm{O}_{2}$ and $\mathrm{pH}$ sensor NPs are used, although there is a strong need for mapping and visualizing other analytes to understand a range of biogeochemical processes. Analytesensitive optical sensor NPs are under rapid development especially for biomedical applications, which will also enable novel sensor NP-based applications in aquatic systems. Potentially applicable NPs already exists (see Tables 2, 3, 4, and 5), which have not yet been used in aquatic systems but are promising e.g. due to their low toxicity. To further realize this potential, more interaction between sensor developers and environmental scientists is needed. New tools enable biologists to ask novel questions and to understand complex systems better. At the same time chemists and material scientists can profit from a more application-driven approach for developing new sensors, which are functional in specific natural systems and help address important biological and biogeochemical questions.

Table 2 summarizes optical, $\mathrm{pH}$ sensitive NPs. Only one NP material, HPTS(DHA) 3 , has been used so far in an aquatic application, namely the fabrication of artificial sediment to visualize $\mathrm{pH}$ dynamics in the rhizosphere of seagrass. The advantage of using this dye is the lipophilic side chain, which allows the use of an easy precipitation technique for NP fabrication. A disadvantage, however, is that it is not

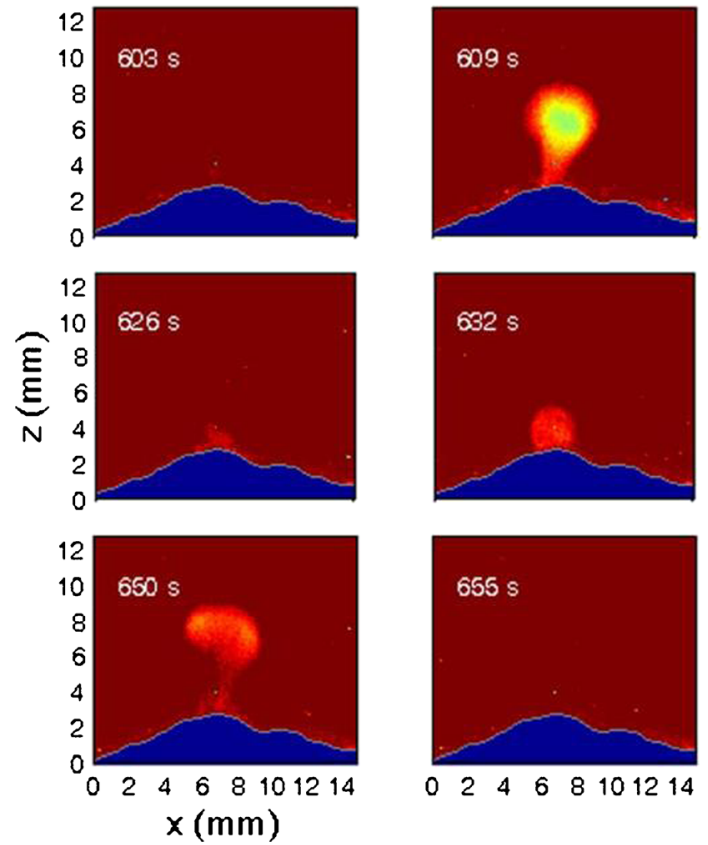

Fig. $12 \mathrm{O}_{2}$ dynamics at the sediment water interface around the burrow of an insect larvae determined with $\mathrm{O}_{2}$-sensitive nanoparticles in the overlaying water. Color-coded images show changes in the dissolved $\mathrm{O}_{2}$
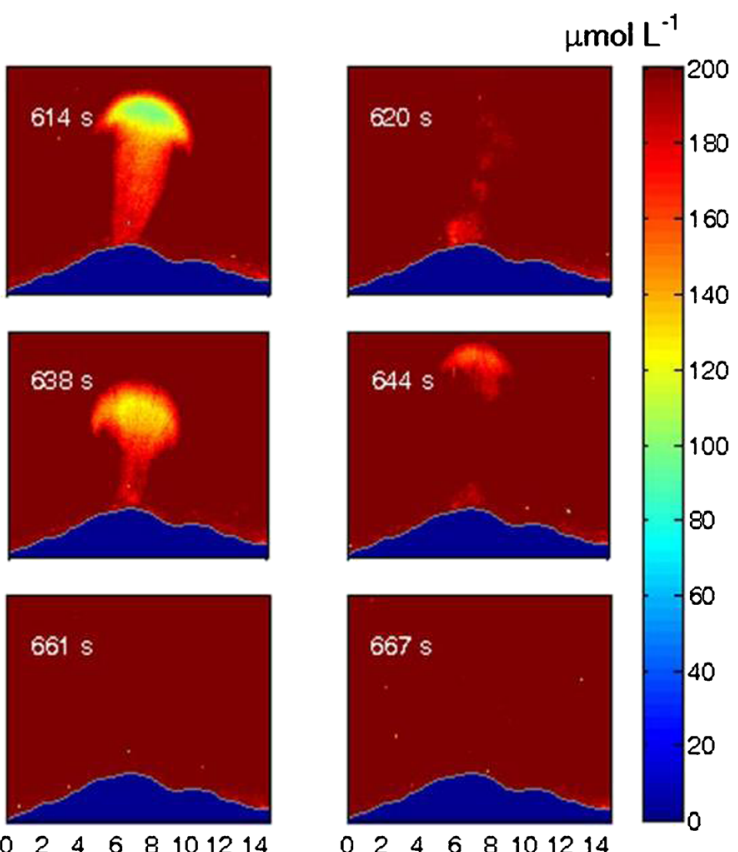

2468101214
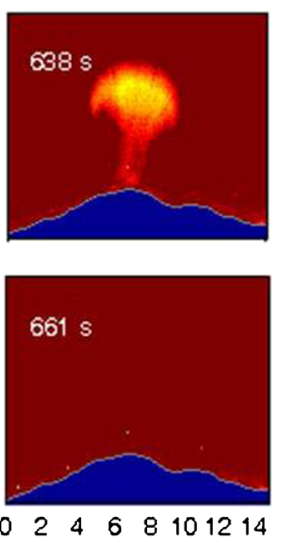

02468101214

over time due to pumping activity of the larvae. No $\mathrm{O}_{2}$ concentration was determined for the sediment (here blue). Reproduced from [56], () 2016 Association for the Sciences of Limnology and Oceanography 
commercially available, but the synthesis is described in the literature [128]. This is of course limiting for application oriented groups without the possibility to do chemical synthesis.

The other described dyes in Table 2 are suitable but have hitherto not been used in aquatic applications. All together they cover $\mathrm{p} K_{\mathrm{a}}$ values from 5.6 to 8.3 (depending on temperature and salinity), covering an operational range of $\mathrm{pH}$ values between 4.6 and 9.3. As a rule of thumb - imaging can be done within $\pm 1 \mathrm{pH}$ units of the $\mathrm{p} K_{\mathrm{a}}$. Although this covers the most relevant physiological range, application-dependent $\mathrm{pH}$ values outside of this span can be of interest as well, in order to visualize local minima or maxima.

Table 3 summarizes the most frequently used $\mathrm{O}_{2}$-sensitive NP and MP systems. Analyte-wise, $\mathrm{O}_{2}-$ sensitive OSPs are the most established systems. They have been broadly applied in aquatic research spanning from being incorporated in artificial sediment, over being used in the gut interior of copepods, to being spray painted on complex structures such as coral surfaces. They have also been used in bioprinting and to visualize surface dynamics of sediments. Their success can partly be attributed to their use of commercially available dyes (PtTFPP and MY can both be purchased), but also to their high (photo)stability. OSP preparation can be done e.g. with the very simple precipitation technique; they have long shelf lives and have a broad dynamic range in relevant concentrations $\left(0-540 \mu \mathrm{mol} \mathrm{O}_{2} \mathrm{~L}^{-1}\right)$.

Ideally, even higher $\mathrm{O}_{2}$ concentrations should be possible to resolve, as some photo-active biological systems can produce $\mathrm{O}_{2}$ concentrations $>1000 \mu \mathrm{mol} \mathrm{O}_{2} \mathrm{~L}^{-1}$. Many of the dyes summarized in Table 3 are possible candidates, such as $\operatorname{Ir}(\mathrm{Cs})_{2}$ (acac), PtOEKP, or PtOEP that all show a dynamic range up to almost $1400 \mu \mathrm{mol} \mathrm{O} \mathrm{L}^{-1}$ (100\% oxygen saturation). Also trace sensors can be of interest for e.g. respiration or $\mathrm{O}_{2}$ depletion measurements. One possible dye here is PdTPTBPF (emitting in the NIR).

The wide array of potential candidates to choose from for aquatic applications is beneficial for tailoring the system to specific needs. For instance the luminescent dyes can be chosen to avoid an overlap of the emission spectrum with e.g. chlorophyll fluorescence, calcite luminescence, or luminescence frequently observed in marine organisms such as corals or anemones. Here we recommend measuring background fluorescence prior to choosing a dye system, as emission wavelengths can be influenced by the sample composition or change from organism to organism.

Table 4 summarizes temperature sensitive MPs and NPs, which can be potentially used in aquatic systems. Temperature-sensitive OSPs can be of great importance as luminescence processes are in general temperature dependent, and these particles can be used to compensate for temperature effects in other dye systems. We expect future developments, where the incorporation of multiple analyte-sensitive dyes within the same OSP matrix will increase in importance.
Planar optode systems, which are capable of dual sensing (e.g. $\mathrm{O}_{2}$ and $\mathrm{T}[97,129,130]$, or $\mathrm{pH}$ and $\mathrm{O}_{2}[32,57]$ ) are gaining popularity, and we believe it is only a matter of time for NPs or MPs to follow that trend. Ranges from below $0{ }^{\circ} \mathrm{C}$ (around the freezing point of e.g. highly saline seawater) to up $\sim 100{ }^{\circ} \mathrm{C}$ (or even higher) can be of interest, to span samples from cold seawater, over hot springs, to even hydrothermal vents.

Different ion-sensitive dyes have been reported for medical and immunobiological applications and are summarized as potential candidates for aquatic applications in Table 5. Here it needs of course to be evaluated, which analytes are relevant for aquatic systems. In our opinion, all of the analytes mentioned in Table 5 can be of interest in different fields of aquatic research.

Copper and zinc concentrations can e.g. be toxic at even low concentrations to marine organisms. Schuler and coworkers [132] summarize data on copper toxicity due to short term, chronic or acute copper exposure on various fresh- and saltwater organisms. Concentrations are usually low as copper is complexed, however, can be locally increased by e.g. ship wrecks, anti-fouling paint [133], or sewage discharges [134]. Concentration ranges of interest are sample dependent and may vary greatly from pristine rivers, over marinas to mining regions (e.g. reported up to $48 \mu^{-1} \mathrm{~g} \mathrm{~L}^{-1}$ (or $\sim 750 \mathrm{nmol} \mathrm{L}^{-1}$ ) at a coastal area in Norther Chile [135]). Overall concentrations are however expected in low nmol $\mathrm{L}^{-1}$ ranges [136]. For concentration ranges of interest we refer to the book "Bioaccumulation in Marine Organisms" by Jerry Neff, who summarized among other analytes published zinc [137] and copper [138] concentrations in different aquatic environments. Very promising research is done in this field, with novel approaches outside of polymeric OSPs; i.e. by using surface modified magnetic beads [139] or quantum dots [140]; just to name a few.

Calcium is of course of major importance in marine systems; e.g. calcification rates have been investigated in correlation to photosynthesis in corals [141], but also plays an important role in freshwater systems, including lake water concentrations and bottom depositions [142] or drinking water [143]. Concentration levels are estimated in the $\mathrm{mmol} \mathrm{L}^{-1}$ range, are however sample dependent and should be looked up prior to conducting experiments. For depletion or oversaturation experiments higher and lower concentration ranges should however be measurable as well.

Potassium sensing of course has to deal with a high background concentrations in (sea)water. Inland waters are reported with minimal concentrations between 1 and $5 \mu \mathrm{mol} \mathrm{L}^{-1}$ but in general not exceeding $10 \mu \mathrm{mol} \mathrm{L}^{-1}$ [144]. Seawater concentrations (which of course depend on salinity) are estimated with $\sim 9700 \mu \mathrm{mol} \mathrm{L}^{-1}$. Increased amounts of potassium can be found in inland waters close to seawater due to sea-spray and it being transported by rain [144] Thus, applying increasing 
$\mathrm{K}^{+}$gradients on freshwater organisms or decreasing concentrations on seawater organisms could be a potential application; especially within organisms (e.g. feeding of OSPs) to visualize how the specific organism can compensate for this ion imbalance. Thus, application-specific potassium-ion sensors should be able to resolve concentrations exceeding the physiological concentration present in the specific sample. Other potential applications include monitoring of fish gills, clams or inside organisms to monitor physiological conditions. It is essential for applications, however, that the potassium sensitive material shows no cross-sensitivity to other ions such as sodium, which is present in abundance.

Chloride sensors can be of interest to monitor salinity changes e.g. in intertidal samples, where a dynamic salinity range spanning from 0 to hypersaline conditions is required. Additional applications, which are relevant for all other mentioned sensor materials are feeding experiments, or measurements in the gut, similarly to the copepod application described by Glud and coworkers [56]. Salinity gradients in the seawater have also been shown to influence the swimming performance and respiration of certain perch species [145]. Combined measurements of $\mathrm{Cl}^{-}$ions and $\mathrm{O}_{2}$ concentration on e.g. the fish gills could thus be of great interest.

When comparing OSPs to other well-established techniques such as (optical) microsensors or planar optodes, their major advantage is that they can be used for chemical imaging in and around structurally complex samples. While such mapping can also be done with microsensors, only a limited amount of measurements is typically feasible in a specific sample without imposing disturbances or other changes in sample conditions. This results in a low spatio-temporal coverage and extrapolation of such data can be very challenging in heterogeneous, dynamic systems. Planar optodes can only map chemical gradients below or around structures in direct contact with the sensor foil and are thus more suitable for samples pressed onto or growing directly on the foil. However, OSPs also have limitations and several aspects need to be considered when using them for biological studies. Potential toxicity of the particles is a major issue, which needs to be evaluated carefully in each application and for each OSP type. In this aspect, more work is needed in particular when it comes to uptake of particles into cells and tissues.

Other issues include optical interferences such as scattering, background fluorescence and camera related artefacts. Camera systems have a certain depth of field, meaning a certain plane is in focus, but other areas might not be. This can distort the results, especially when working with very uneven surfaces. It is important to keep this in mind when adjusting the focal point of the camera on a sample and later when analyzing the images. We strongly believe, or hope, that future developments in regard to camera systems will increase the depth of field, enable real 3D resolution of OSPs, or a more modular option to move the camera system around the sample. Other issues might arise when working with living systems such as corals. Being covered with a polymer layer can be stressful for such sensitive systems and they might try to remove them by excessive mucus production. They can also show a stress response to the handling procedure, which might result in unexpected behavior. Equilibration times should be allowed; however, sometimes compromises might be necessary when working with such complex systems.

In conclusion, optical sensor NPs are emerging novel tools with tremendous potential for further application in aquatic science. First applications have demonstrated the versatility and broad applicability of sensor NPs for i) mapping the chemical landscape of complex structures such as coral surfaces $[25,52]$ and the rhizosphere of aquatic plants $[53,54]$, ii) incorporation of sensor NPs (or MPs) in 3D bioprinted living constructs [67], and iii) visualization of chemical dynamics at the water-sediment interface [55] or inside dead and living organism [56]. OSPs can be modified for optimal use in different environments by changing the sensor chemistry, matrix material and additives, as well as other variables such as size and surface charge for optimizing immobilization/ internalization in samples. There exists a plethora of various readout options for OSPs ranging from simple macroscopic ratio imaging, advanced light sheet and confocal microscopy, over luminescence intensity to lifetime measurements at different spatial scales in aquatic systems and organisms.

Acknowledgements This study was supported by a Sapere-Aude Advanced grant from the Independent Research Fund Denmark (DFF1323-00065B; MK), project grants from the Independent Research Fund Denmark | Natural Sciences (DFF-8021-00308B; MK) \& Technical and Production Sciences (DFF-8022-00301B and DFF-4184-00515B; MK), the Villum Foundation (Grant no. 00023073; MK), the Poul Due Jensen Foundation (KK), and a Carlsberg Foundation Postdoctoral Fellowship (CF16-0899; KEB).

Compliance with ethical standards The author(s) declare that they have no competing interests.

Publisher's Note Springer Nature remains neutral with regard to jurisdictional claims in published maps and institutional affiliations.

\section{References}

1. Borisov SM, Klimant I (2008) Optical nanosensors - smart tools in bioanalytics. Analyst 133:1302-1307. https://doi.org/10.1039/ b805432k

2. Papkovsky DB, Dmitriev RI (2013) Biological detection by optical oxygen sensing. Chem Soc Rev 42:8700-8732. https://doi.org/ $10.1039 / \mathrm{c} 3 \mathrm{cs} 60131 \mathrm{e}$

3. Wencel D, Abel T, McDonagh C (2014) Optical chemical pH sensors. Anal Chem 86:15-29. https://doi.org/10.1021/ac4035168

4. McDonagh C, Burke CS, MacCraith BD (2008) Optical chemical sensors. Chem Rev 108:400-422. https://doi.org/10.1021/ cr068102g 
5. Murthy SK (2007) Nanoparticles in modern medicine: state of the art and future challenges. Int $J$ Nanomedicine 2:129 141. https://doi.org/10.1016/j.cell.2015.01.054

6. Glud RN, Wenzhöfer F, Tengberg A, Middelboe M, Oguri K, Kitazato H (2005) Distribution of oxygen in surface sediments from central Sagami Bay, Japan: in situ measurements by microelectrodes and planar optodes. Deep Sea Res Part I Oceanogr Res Pap 52:1974-1987. https://doi.org/10.1016/j.dsr.2005.05.004

7. Moore C, Barnard A, Fietzek P, Lewis MR, Sosik HM, White S, Zielinski O (2009) Optical tools for ocean monitoring and research. Ocean Sci 5:661-684. https://doi.org/10.5194/os-5-6612009

8. Hancke K, Sorell BK, Lund-Hansen LC, Larsen M, Hancke T, Glud RN (2014) Effects of temperature and irradiance on a benthic microalgal community: a combined two-dimensional oxygen and fluorescence imaging approach. Limnol Oceanogr 59:1599-1611. https://doi.org/10.4319/lo.2014.59.5.1599

9. Ge X, Kostov Y, Henderson R, Selock N, Rao G (2014) A lowcost fluorescent sensor for pCO2 measurements. Chemosensors 2: 108-120. https://doi.org/10.3390/chemosensors2020108

10. Borisov SM (2018) Fundamentals of quenched and rational design of sensor materials. In: Papkovsky DB, Dmitriev RI (eds) Quenched-phosphorescence detection of molecular oxygen: applications in life science, 1st edn. The Royal Society of Chemistry, Cambridge, pp 1-18

11. Lobnik A, Turel M, Urek S̆ (2012) Optical chemical sensors: design and applications. In: Wang W (ed) Advances in Chemical Sensors. IntechOpen, pp 1-28

12. Mistlberger G, Crespo GA, Bakker E (2014) Ionophore-based optical sensors. Annu Rev Anal Chem 7:483-512. https://doi. org/10.1146/annurev-anchem-071213-020307

13. Wolfbeis OS (2005) Materials for fluorescence-based optical chemical sensors. J Mater Chem 15:2657-2669. https://doi.org/ 10.1039/b501536g

14. Meier RJ, Fischer LH, Wolfbeis OS, Schäferling M (2013) Referenced luminescent sensing and imaging with digital color cameras: a comparative study. Sensors Actuators B 177:500506. https://doi.org/10.1016/j.snb.2012.11.041

15. Koren K, Kühl M (2018) Optical O2 sensing in aquatic systems and organisms. In: Papkovsky DB, Dmitriev RI (eds) Quenchedphosphorescence detection of molecular oxygen: applications in life science, 1 st edn. The Royal Society of Chemistry, Cambridge, pp 145-174

16. Wang X, Wolfbeis OS (2014) Optical methods for sensing and imaging oxygen: materials, spectroscopies and applications. Chem Soc Rev 43:3666-3761. https://doi.org/10.1039/ c4cs00039k

17. Wolfbeis OS (2015) Luminescent sensing and imaging of oxygen: fierce competition to the Clark electrode. Bioessays 37:921-928. https://doi.org/10.1002/bies.201500002

18. Körtzinger A, Schimanski J, Send U (2004) High quality oxygen measurements from profiling floats: a promising new technique. J Atmos Ocean Technol 22:302-308. https://doi.org/10.1175/ JTECH1701.1

19. Sevilla III F, Narayanaswamy R (2003) Optical chemical sensors and biosensors. In: Alegret S (ed) Comprehensive Analytical Chemistry. Elsevier B.V., pp 413-435

20. Holst GA, Klimant I, Kühl M, Kohls O (1999) Optical microsensors and microprobes. In: Varney M (ed) Chemical sensors in oceanography. Gordon Breach Science Publishers

21. Wang X, Wolfbeis OS (2016) Fiber-optic chemical sensors and biosensors (2013 - 2015). Anal Chem 88:203-227. https://doi.org/10.1021/acs.analchem.5b04298

22. Klimant I, Meyer V, Kühl M (1995) Fiber-optic oxygen microsensors, a new tool in aquatic biology. Limnol Oceanogr 40:1159-1165. https://doi.org/10.4319/lo.1995.40.6.1159
23. Klimant I, Kühl M, Glud RN, Holst G (1997) Optical measurement of oxygen and temperature in microscale: strategies and biological applications. Sensors Actuators B 38-39:29-37. https://doi.org/10.1016/S0925-4005(97)80168-2

24. Neurauter G, Klimant I, Wolfbeis OS (2000) Fiber-optic microsensor for high resolution $\mathrm{pCO} 2$ sensing in marine environment. Fresenius J Anal Chem 366:481-487. https://doi.org/10.1007/ s002160050097

25. Fabricius-Dyg J, Mistlberger G, Staal M, Borisov SM, Klimant I, Kühl M (2012) Imaging of surface O2 dynamics in corals with magnetic micro optode particles. Mar Biol 159:1621-1631. https://doi.org/10.1007/s00227-012-1920-y

26. Kühl M (2005) Optical microsensors for analysis of microbial communities. In: Leadbetter JR. In: Methods in enzymology, vol 397, pp 166-199

27. Herbert NA, Bröhl S, Springer K, Kunzmann A (2017) Clownfish in hypoxic anemones replenish host $\mathrm{O} 2$ at only localised scales. Sci Rep 7:1-10. https://doi.org/10.1038/s41598-017-06695-x

28. Jokic T, Borisov SM, Saf R, Nielsen DA, Kühl M, Klimant I (2012) Highly Photostable near-infrared fluorescent $\mathrm{pH}$ indicators and sensors based on BF2-chelated Tetraarylazadipyrromethene dyes. Anal Chem 84:6723-6730. https://doi.org/10.1021/ ac3011796

29. Holtappels M, Noss C, Hancke K, Cathalot C, McGinnis DF, Lorke A, Glud RN (2015) Aquatic eddy correlation: quantifying the artificial flux caused by stirring-sensitive O2 sensors. PLoS One 10:1-20. https://doi.org/10.1371/journal.pone.0116564

30. Glud RN, Ramsing NB, Gundersen JK, Klimant I (1996) Planar optrodes: a new tool for fine scale measurements of twodimensional O2 distribution in benthic communities. Mar Ecol Prog Ser 140:217-226. https://doi.org/10.3354/meps140217

31. Larsen M, Borisov SM, Grunwald B, Klimant I, Glud RN (2011) A simple and inexpensive high resolution color ratiometric planar optode imaging approach: application to oxygen and $\mathrm{pH}$ sensing. Limnol Oceanogr Methods 9:348-360. https://doi.org/10.4319/ lom.2011.9.348

32. Moßhammer M, Strobl M, Kühl M, Klimant I, Borisov SM, Koren K (2016) Design and application of an optical sensor for simultaneous imaging of $\mathrm{pH}$ and dissolved $\mathrm{O} 2$ with low crosstalk. ACS Sensors 1:681-687. https://doi.org/10.1021/ acssensors.6b00071

33. Blossfeld S, Gansert D (2007) A novel non-invasive optical method for quantitative visualization of $\mathrm{pH}$ dynamics in the rhizosphere of plants. Plant Cell Environ 30:176-186. https://doi.org/10.1111/ j.1365-3040.2006.01616.x

34. Strobl M, Rappitsch T, Borisov SM, Mayr T, Klimant I (2015) NIR-emitting aza-BODIPY dyes - new building blocks for broadrange optical pH sensors. Analyst 140:7150-7153. https://doi.org/ 10.1039/C5AN01389E

35. Hulth S, Aller RC, Engström P, Selander E (2002) A pH plate fluorosensor (optode) for early diagenetic studies of marine sediments. Limnol Oceanogr 47:212-220. https://doi.org/10.4319/lo. 2002.47.1.0212

36. Zhu Q, Aller RC (2013) Planar fluorescence sensors for twodimensional measurements of $\mathrm{H} 2 \mathrm{~S}$ distributions and dynamics in sedimentary deposits. Mar Chem 157:49-58. https://doi.org/10. 1016/j.marchem.2013.08.001

37. Zhu Q, Aller RC, Fan Y (2006) A new ratiometric, planar fluorosensor for measuring high resolution, two-dimensional pCO2 distributions in marine sediments. Mar Chem 101:40-53. https://doi.org/10.1016/j.marchem.2006.01.002

38. Schroeder CR, Neurauter G, Klimant I (2007) Luminescent dual sensor for time-resolved imaging of $\mathrm{pCO} 2$ and $\mathrm{pO} 2$ in aquatic systems. Microchim Acta 158:205-218. https://doi.org/10.1007/ s00604-006-0696-5 
39. Zhu Q, Aller RC (2010) A rapid response, planar fluorosensor for measuring two-dimensional pCO2 distributions and dynamics in marine sediments. Limnol Oceanogr Methods 8:326336. https://doi.org/10.4319/lom.2010.8.326

40. Strömberg N, Hulth S (2005) Assessing an imaging ammonium sensor using time correlated pixel-by-pixel calibration. Anal Chim Acta 550:61-68. https://doi.org/10.1016/j.aca.2005.06.074

41. Waich K, Mayr T, Klimant I (2008) Fluorescence sensors for trace monitoring of dissolved ammonia. Talanta 77:6672. https://doi.org/10.1016/j.talanta.2008.05.058

42. Fischer JP, Wenzhöfer F (2010) A novel planar optode setup for concurrent oxygen and light field imaging: application to a benthic phototrophic community. Limnol Oceanogr Methods 8:254-268. https://doi.org/10.4319/lom.2010.8.254

43. Glud RN, Tengberg A, Kühl M, Hall POJ, Klimant I (2001) An in situ instrument for planar $\mathrm{O} 2$ optode measurements at benthic interfaces. Limnol Oceanogr 46:2073-2080. https://doi.org/10. 4319/lo.2001.46.8.2073

44. Frederiksen MS, Glud RN (2006) Oxygen dynamics in the rhizosphere of Zostera marina: a two-dimensional planar optode study. Limnol Oceanogr 51:1072-1083. https://doi.org/10.4319/lo.2006. 51.2.1072

45. Brodersen KE, Koren K, Moßhammer M, Ralph PJ, Kühl M, Santner J (2017) Seagrass-mediated phosphorus and Iron Solubilization in tropical sediments. Environ Sci Technol 51: 14155-14163. https://doi.org/10.1021/acs.est.7b03878

46. Koop-Jakobsen K, Wenzhöfer F (2015) The dynamics of plantmediated sediment oxygenation in Spartina anglica rhizospheres a planar Optode study. Estuar Coasts 38:951-963. https://doi.org/ 10.1007/s12237-014-9861-y

47. Jensen SI, Kühl M, Glud RN, Jørgensen LB, Priemé A (2005) Oxic microzones and radial oxygen loss from roots of Zostera marina. Mar Ecol Prog Ser 293:49-58

48. Kühl M, Holst G, Larkum AWD, Ralph PJ (2008) Imaging of oxygen dynamics within the endolithic algal community of the massive coral Porites lobata. J Phycol 44:541-550. https://doi. org/10.1111/j.1529-8817.2008.00506.x

49. Kühl M, Behrendt L, Trampe E, Qvortrup K, Schreiber U, Borisov SM, Klimant I, Larkum AWD (2012) Microenvironmental ecology of the chlorophyll b-containing symbiotic cyanobacterium Prochloron in the Didemnid ascidian Lissoclinum patella. Front Microbiol 3:1-18. https://doi.org/10.3389/fmicb.2012.00402

50. Santner J, Larsen M, Kreuzeder A, Glud RN (2015) Two decades of chemical imaging of solutes in sediments and soils - a review. Anal Chim Acta 878:9-42. https://doi.org/10.1016/j.aca.2015.02. 006

51. Kühl M, Rickelt LF, Thar R (2007) Combined imaging of bacteria and oxygen in biofilms. Appl Environ Microbiol 73:6289-6295. https://doi.org/10.1128/AEM.01574-07

52. Koren K, Jakobsen SL, Kühl M (2016) In-vivo imaging of O2 dynamics on coral surfaces spray-painted with sensor nanoparticles. Sensors Actuators B Chem 237:1095-1101. https://doi.org/ 10.1016/j.snb.2016.05.147

53. Koren K, Brodersen KE, Jakobsen SL, Kühl M (2015) Optical sensor nanoparticles in artificial sediments-a new tool to visualize $\mathrm{O} 2$ dynamics around the rhizome and roots of seagrasses. Environ Sci Technol 49:2286-2292. https://doi.org/10.1021/es505734b

54. Brodersen KE, Koren K, Lichtenberg M, Kühl M (2016) Nanoparticle-based measurements of $\mathrm{pH}$ and $\mathrm{O} 2$ dynamics in the rhizosphere of Zostera marina L.: effects of temperature elevation and light-dark transitions. Plant Cell Environ 39:16191630. https://doi.org/10.1111/pce.12740

55. Murniati E, Gross D, Herlina H, Hancke K, Glud RN, Lorke A (2016) Oxygen imaging at the sediment-water interface using lifetime-based laser induced fluorescence ( $\tau$ LIF) of nano-sized particles. Limnol Oceanogr Methods 14:506-517. https://doi. org/10.1002/lom3.10108

56. Glud RN, Grossart HP, Larsen M, Tang KW, Arendt KE, Rysgaard S, Thamdrup B, Gissel Nielsen T (2015) Copepod carcasses as microbial hot spots for pelagic denitrification. Limnol Oceanogr 60:2026-2036. https://doi.org/10.1002/lno.10149

57. Ehgartner J, Wiltsche H, Borisov SM, Mayr T (2014) Low cost referenced luminescent imaging of oxygen and $\mathrm{pH}$ with a 2CCD colour near infrared camera. Analyst 139:4924-4933. https://doi.org/10.1039/C4AN00783B

58. Koren K, Kühl M (2015) A simple laminated paper-based sensor for temperature sensing and imaging. Sensors Actuators B Chem 210:124-128. https://doi.org/10.1016/j.snb.2014.12.102

59. Holst G, Kohls O, Klimant I, König B, Kühl M, Richter T (1998) A modular luminescence lifetime imaging system for mapping oxygen distribution in biological samples. Sensors Actuators B $51: 163-170$

60. Holst G, Grunwald B (2001) Luminescence lifetime imaging with transparent oxygen optodes. Sensors Actuators B 74: 78-90. https://doi.org/10.1016/S0925-4005(00)00715-2

61. Quaranta M, Borisov SM, Klimant I (2012) Indicators for optical oxygen sensors. Bioanal Rev 4:115-157. https://doi.org/10.1007/ s12566-012-0032-y

62. Zhang G, Palmer GM, Dewhirst MW, Fraser CL (2009) A dualemissive-materials design concept enables tumour hypoxia imaging. Nat Mater 8:747-751. https://doi.org/10.1038/nmat2509

63. Zhang G, Chen J, Payne SJ, Kooi SE, Demas JN, Fraser CL (2007) Multi-emissive difluoroboron dibenzoylmethane polylactide exhibiting intense fluorescence and oxygensensitive room-temperature phosphorescence. J Am Chem Soc 129:8942-8943. https://doi.org/10.1021/ja0720255

64. Yoshihara T, Yamaguchi Y, Hosaka M, Takeuchi T, Tobita S (2012) Ratiometric molecular sensor for monitoring oxygen levels in living cells. Angew Chemie - Int Ed 51:4148-4151. https://doi. org/10.1002/anie.201107557

65. Xiang H, Zhou L, Feng Y, Cheng J, Wu D, Zhou X (2012) Tunable fluorescent/phosphorescent platinum(II) porphyrinfluorene copolymers for ratiometric dual emissive oxygen sensing. Inorg Chem 51:5208-5212. https://doi.org/10.1021/ ic300040n

66. Khalil GE, Coston C, Crafton J et al (2004) Dual-luminophor pressure-sensitive paint I Ratio of reference to sensor giving a small temperature dependency. Sensors Actuators B 97:13-21. https://doi.org/10.1016/S0925-4005(03)00484-2

67. Trampe E, Koren K, Akkineni AR, Senwitz C, Krujatz F, Lode A, Gelinsky M, Kühl M (2018) Functionalized bioink with optical sensor nanoparticles for $\mathrm{O} 2$ imaging in 3D-bioprinted constructs. Adv Funct Mater 1804411:1804411. https://doi.org/10.1002/ adfm. 201804411

68. Lakowicz JR (2006) Principles of fluorescence spectroscopy, 3rd ed. Springer US

69. Valeur B (2001) Molecular fluorescence: principles and applications. Wiley-VCH

70. Carraway ER, Demas JN, DeGraff BA, Bacon JR (1991) Photophysics and photochemistry of oxygen sensors based on luminescent transition-metal complexes. Anal Chem 63: $337-342$

71. Demas JN, De Graff BA, Xu W (1995) Modeling of luminescence quenching-based sensors: comparison of multisite and nonlinear gas solubility models. Anal Chem 67:13771380. https://doi.org/10.1021/ac00104a012

72. Ballew RM, Demas JN (1989) Error analysis of the rapid lifetime determination method for the evaluation of single exponential decays. Analytical 61:30-33. https://doi.org/10.1016/S00032670(00)80210-X 
73. Schreml S, Meier RJ, Wolfbeis OS, Landthaler M, Szeimies RM, Babilas P (2011) 2D luminescence imaging of $\mathrm{pH}$ in vivo. Proc Natl Acad Sci U S A 108:2432-2437. https://doi.org/10.1073/ pnas. 1006945108

74. Becker W (2012) Fluorescence lifetime imaging - techniques and applications. J Microsc 247:119-136. https://doi.org/10.1111/j. 1365-2818.2012.03618.x

75. Kennedy GT, Elson DS, Hares JD, Munro I, Poher V, French PMW, Neil MAA (2008) Fluorescence lifetime imaging using light emitting diodes. J Phys D Appl Phys 41(6):094012. https:// doi.org/10.1117/12.701088

76. Franke R, Holst GA (2015) Frequency-domain fluorescence lifetime imaging system (pco.flim) based on a in-pixel dual tap control CMOS image sensor. In: Farkas DL, Nicolau D V., Leif RC (eds) Proceedings of SPIE 93281, Imaging, Manipulation, and Analysis of Biomolecules, Cells, and Tissues XIII. San Francisco, pp 1-19

77. Stich MIJ, Fischer LH, Wolfbeis OS (2010) Multiple fluorescent chemical sensing and imaging. Chem Soc Rev 39:3102-3114. https://doi.org/10.1039/b909635n

78. Larsen M, Santner J, Oburger E, Wenzel WW, Glud RN (2015) $\mathrm{O} 2$ dynamics in the rhizosphere of young rice plants (Oryza sativa L.) as studied by planar optodes. Plant Soil 390:279292. https://doi.org/10.1007/s11104-015-2382-z

79. Borisov SM, Klimant I (2009) Luminescent nanobeads for optical sensing and imaging of dissolved oxygen. Microchim Acta 164:715. https://doi.org/10.1007/s00604-008-0047-9

80. Liebsch G, Klimant I, Krause C, Wolfbeis OS (2001) Fluorescent imaging of $\mathrm{pH}$ with optical sensors using time domain dual lifetime referencing. Anal Chem 73:4354-4363. https://doi.org/10. $1021 / \mathrm{ac} 0100852$

81. Staal M, Borisov SM, Rickelt LF, Klimant I, Kühl M (2011) Ultrabright planar optodes for luminescence life-time based microscopic imaging of $\mathrm{O} 2$ dynamics in biofilms. J Microbiol Methods 85:67-74

82. Becker W, Shcheslavskiy V (2017) Simultaneous phosphorescence and fluorescence lifetime imaging by multi-dimensional TCSPC and multi-pulse excitation. In: Dimitriev R (ed) Multiparametric live cell microscopy of 3D tissue models. Advances in experimental medicine and biology. Springer, pp 19-31

83. Suhling K, Hirvonen LM, Levitt JA, Chung PH, Tregidgo C, le Marois A, Rusakov DA, Zheng K, Ameer-Beg S, Poland S, Coelho S, Henderson R, Krstajic N (2015) Fluorescence lifetime imaging (FLIM): basic concepts and some recent developments. Med Photonics 27:3-40. https://doi.org/10. 1016/j.medpho.2014.12.001

84. Chen H, Holst G, Gratton E (2015) Modulated CMOS camera for fluorescence lifetime microscopy. Microsc Res Tech 78:10751081. https://doi.org/10.1002/jemt.22587

85. Chen H, Gratton E (2013) A practical implementation of multifrequency widefield frequency-domain fluorescence lifetime imaging microscopy. Microsc Res Tech 76:282-289. https://doi.org/10. 1002/jemt.22165

86. Booth MJ, Wilson T (2004) Low-cost, frequency-domain, fluorescence lifetime confocal microscopy. J Microsc 214:3642. https://doi.org/10.1111/j.0022-2720.2004.01316.x

87. Mistlberger G, Chojnacki P, Klimant I (2008) Magnetic sensor particles: an optimized magnetic separator with an optical window. J Phys D Appl Phys 41:085003. https://doi.org/10.1088/ 0022-3727/41/8/085003

88. Mistlberger G, Koren K, Scheucher E, Aigner D, Borisov SM, Zankel A, Pölt P, Klimant I (2010) Multifunctional magnetic optical sensor particles with tunable sizes for monitoring metabolic parameters and as a basis for Nanotherapeutics. Adv Funct Mater 20:1842-1851. https://doi.org/10.1002/adfm.201000321
89. Chojnacki P, Mistlberger G, Klimant I (2007) Separable magnetic sensors for the optical determination of oxygen. Angew Chemie Int Ed 46:8850-8853. https://doi.org/10.1002/anie.200702068

90. Wolfbeis OS (2015) An overview of nanoparticles commonly used in fluorescent bioimaging. Chem Soc Rev 44:47434768. https://doi.org/10.1039/c4cs00392f

91. Lee Y-EK, Kopelman R (2012) Nanoparticle PEBBLE sensors in live cells. Methods in Enzymology. Elsevier Inc., In, pp 419-470

92. Cao Y, Koo YL, Kopelman R (2004) Poly(decyl methacrylate)based fluorescent PEBBLE swarm nanosensors for measuring dissolved oxygen in biosamples. Analyst 129:745-750

93. Clark HA, Hoyer M, Parus S, Philbert MA, Kopelman R (1999) Optochemical nanosensors and subcellular applications in living cells. Microchim Acta 131:121-128

94. Borisov SM, Mayr T, Klimant I (2008) Poly(styrene-blockvinylpyrrolidone) beads as a versatile material for simple fabrication of optical nanosensors. Anal Chem 80:573582. https://doi.org/10.1021/ac071374e

95. Borisov SM, Herrod DL, Klimant I (2009) Fluorescent poly (styrene-block- vinylpyrrolidone) nanobeads for optical sensing of pH. Sensors Actuators B Chem 139:52-58. https://doi.org/10. 1016/j.snb.2008.08.028

96. Sun L-N, Yu J, Peng H, Zhang JZ, Shi LY, Wolfbeis OS (2010) Temperature-sensitive luminescent nanoparticles and films based on a terbium(III) complex probe. J Phys Chem C 114:1264212648

97. Fischer LH, Borisov SM, Schaeferling M, Klimant I, Wolfbeis OS (2010) Dual sensing of pO2 and temperature using a waterbased and sprayable fluorescent paint. Analyst 135:1224 1229. https://doi.org/10.1039/b927255k

98. Brasuel M, Kopelman R, Miller TJ, Tjalkens R, Philbert MA (2001) Fluorescent nanosensors for intracellular chemical analysis: Decyl methacrylate liquid polymer matrix and ion-exchange-based potassium PEBBLE sensors with realtime application to viable rat C6 glioma cells. Anal Chem 73:2221-2228. https://doi.org/10.1021/ac0012041

99. Müller BJ, Borisov SM, Klimant I (2016) Red- to NIR-emitting, BODIPY-based, K+-selective Fluoroionophores and sensing materials. Adv Funct Mater 26:7697-7707. https://doi.org/10.1002/ adfm. 201603822

100. Müller BJ, Zhdanov AV, Borisov SM, Foley T, Okkelman IA, Tsytsarev V, Tang Q, Erzurumlu RS, Chen Y, Zhang H, Toncelli C, Klimant I, Papkovsky DB, Dmitriev RI (2018) Nanoparticle-based Fluoroionophore for analysis of potassium ion dynamics in 3D tissue models and in vivo. Adv Funct Mater 28:1-12. https://doi.org/10.1002/adfm.201704598

101. Koo YEL, Cao Y, Kopelman R, Koo SM, Brasuel M, Philbert MA (2004) Real-time measurements of dissolved oxygen inside live cells by organically modified silicate fluorescent nanosensors. Anal Chem 76:2498-2505. https://doi.org/10.1021/ac035493f

102. Sumner JP, Westerberg NM, Stoddard AK, Fierke CA, Kopelman $\mathrm{R}$ (2006) $\mathrm{Cu}+-$ and $\mathrm{Cu} 2+-$ sensitive PEBBLE fluorescent nanosensors using DsRed as the recognition element. Sensors Actuators B 113:760-767. https://doi.org/10.1016/j.snb.2005.07. 028

103. Xu H, Aylott JW, Kopelman R, Miller TJ, Philbert MA (2001) A real-time ratiometric method for the determination of molecular oxygen inside living cells using sol-gel-based spherical optical nanosensors with applications to rat C6 glioma. Anal Chem 73: 4124-4133. https://doi.org/10.1021/ac0102718

104. Borisov SM, Mayr T, Mistlberger G, Waich K, Koren K, Chojnacki P, Klimant I (2009) Precipitation as a simple and versatile method for preparation of optical nanochemosensors. Talanta 79:1322-1330. https://doi.org/10.1016/j.talanta.2009.05. 041 
105. Kürner JM, Klimant I, Krause C, Preu H, Kunz W, Wolfbeis OS (2001) Inert phosphorescent nanospheres as markers for optical assays. Bioconjug Chem 12:883-889. https://doi.org/10.1021/ bc000130x

106. Rempel GL, Wang H (2015) Microemulsion polymerization. In: Kobayashi S, Müllen K (eds) Encyclopedia of polymeric nanomaterials. Heidelberg, Berlin, pp 1241-1250

107. Mistlberger G, Medina-Castillo AL, Borisov SM, Mayr T, Fernández-Gutiérrez A, Fernandez-Sanchez JF, Klimant I (2011) Mini-emulsion solvent evaporation: a simple and versatile way to magnetic nanosensors. Microchim Acta 172:299 308. https://doi.org/10.1007/s00604-010-0492-0

108. Bonham JA, Faers MA, van Duijneveldt JS (2014) Non-aqueous microgel particles: synthesis, properties and applications. Soft Matter 10:9384-9398. https://doi.org/10.1039/C4SM01834F

109. Desgouilles S, Vauthier C, Bazile D, Vacus J, Grossiord JL, Veillard M, Couvreur P (2003) The Design of Nanoparticles Obtained by solvent evaporation: a comprehensive study. Langmuir 19:9504-9510. https://doi.org/10.1021/la034999q

110. Teodorescu M, Bercea M (2015) Poly(vinylpyrrolidone) - a versatile polymer for biomedical and beyond medical applications. Polym - Plast Technol Eng 54:923-943. https://doi.org/10.1080/ 03602559.2014.979506

111. Lin J, Brown CW (1997) Sol-gel glass as a matrix for chemical and biochemical sensing. Trends Anal Chem 16:200-211

112. Innocenzi P (2016) From the precursor to a sol. In: The Sol to Gel Transition, SpringerBr Springer, Alghero, pp 7-25

113. Riccò R, Nizzero S, Penna E, Meneghello A, Cretaio E, Enrichi F (2018) Ultra-small dye-doped silica nanoparticles via modified sol-gel technique. J Nanopart Res 20:1-9. https://doi.org/10. 1007/s11051-018-4227-1

114. Geddes CD, Lakowics JR (2002) Topics in fluorescence spectroscopy. Volume 10. Advanced Concepts in Fluorescence Spectroscopy - Part B: Macromolecular Sensing. Springer

115. Uhlmann DR, Teowee G, Boulton J (1997) The future of sol-gel science and technology. J Sol-Gel Sci Technol 8:1083-1091. https://doi.org/10.1007/BF02436988

116. Sakka S (1989) Formation of particles in sol-gel process. KONA 7:106-118

117. Mistlberger G, Borisov SM, Klimant I (2009) Enhancing performance in optical sensing with magnetic nanoparticles. Sensors Actuators B Chem 139:174-180. https://doi.org/10.1016/j.snb. 2008.11.008

118. Koren K, Mistlberger G, Aigner D, Borisov SM, Zankel A, Pölt P, Klimant I (2010) Characterization of micrometer-sized magnetic optical sensor particles produced via spray-drying. Monatsh Chem 141:691-697. https://doi.org/10.1007/s00706-010-0262-z

119. Sønderholm M, Koren K, Wangpraseurt D, Jensen PØ, Kolpen M, Kragh KN, Bjarnsholt T, Kühl M (2018) Tools for studying growth patterns and chemical dynamics of aggregated Pseudomonas aeruginosa exposed to different electron acceptors in an alginate bead model. NPJ Biofilms Microbiomes 3:1-11. https://doi.org/10.1038/s41522-018-0047-4

120. Meysman FJR, Galaktionov OS, Glud RN, Middelburg JJ (2010) Oxygen penetration around burrows and roots in aquatic sediments. J Mar Res 68:309-336. https://doi.org/10.1357/ 002224010793721406

121. Salih A, Larkum A, Cox G, Kühl M, Hoegh-Guldberg O (2000) Fluorescent pigments in corals are photoprotective. Nature 408: 850-853. https://doi.org/10.1038/35048564

122. Beer S, Vilenkin B, Weil A, Veste M, Susel L, Eshel A (1998) Measuring photosynthetic rates in seagrasses by pulse amplitude modulated (PAM) fluorometry. Mar Ecol Prog Ser 174:293-300. https://doi.org/10.3354/meps 174293

123. Brodersen KE, Nielsen DA, Ralph PJ, Kühl M (2015) Oxic microshield and local $\mathrm{pH}$ enhancement protects Zostera muelleri from sediment derived hydrogen sulphide. New Phytol 205:1264 1276. https://doi.org/10.1111/nph.13124

124. Brodersen KE, Hammer KJ, Schrameyer V, Floytrup A, Rasheed MA, Ralph PJ, Kühl M, Pedersen O (2017) Sediment resuspension and deposition on seagrass leaves impedes internal plant aeration and promotes phytotoxic $\mathrm{H} 2 \mathrm{~S}$ intrusion. Front Plant Sci 8 . https://doi.org/10.3389/fpls.2017.00657

125. Pedersen O, Binzer T, Borum J (2004) Sulphide intrusion in eelgrass (Zostera marina L .). Plant Cell Environ 27:595-602

126. Brodersen KE, Siboni N, Nielsen DA, Pernice M, Ralph PJ, Seymour J, Kühl M (2018) Seagrass rhizosphere microenvironment alters plant-associated microbial community composition. Environ Microbiol 20:2854-2864. https://doi.org/10.1111/14622920.14245

127. Schreiber U (2004) Pule-amplitude-modulation (PAM) Fluorometry and saturation pulse method: an overview. In: Papageorgiou GC, Govindjee (eds) chlorophyll a fluorescence: a signature of photosynthesis. Springer, Dordrecht, pp 279-319

128. Mohr GJ, Werner T, Wolfbeis OS (1995) Application of a novel Lipophilized fluorescent dye in an optical nitrate sensor. J Fluoresc 5:135-138. https://doi.org/10.1007/BF00727530

129. Baleiz̃a C, Nagl S, Schäferling M et al (2008) Dual fluorescence sensor for trace oxygen and temperature with unmatched range and sensitivity. Anal Chem 80:6449-6457. https://doi.org/10. 1021/ac801034p

130. Borisov SM, Vasylevska AS, Krause C, Wolfbeis OS (2006) Composite luminescent material for dual sensing of oxygen and temperature. Adv Funct Mater 16:1536-1542. https://doi.org/10. 1002/adfm.200500778

131. Wang XD, Song XH, He CY, Yang CJ, Chen G, Chen X (2011) Preparation of reversible colorimetric temperature nanosensors and their application in quantitative two-dimensional thermo-imaging. Anal Chem 83:2434-2437. https://doi.org/10.1021/ ac200196y

132. Schuler LJ, Hoang TC, Rand GM (2008) Aquatic risk assessment of copper in freshwater and saltwater ecosystems of South Florida. Ecotoxicology 17:642-659. https://doi. org/10.1007/s10646-008-0236-7

133. Alzieu C, CLaidde D (1993) Copper contamination as a result of antifouling paint regulations? Mar Pollut Bull 26:395-397

134. Victor S, Richmond RH (2005) Effect of copper on fertilization success in the reef coral Acropora surculosa. Mar Pollut Bull 50: 1433-1456. https://doi.org/10.1016/j.marpolbul.2005.09.004

135. Stauber JL, Andrade S, Ramirez M, Adams M, Correa JA (2005) Copper bioavailability in a coastal environment of northern Chile: comparison of bioassay and analytical speciation approaches. Mar Pollut Bull 50:1363-1372. https://doi.org/10.1016/j.marpolbul. 2005.05.008

136. Hirose K (1990) Chemical speciation of trace metals in seawater: implication of particulate trace metals. Mar Chem 28:267-274

137. Neff JM (2002) Zinc in the ocean. In: Bioaccumulation in marine organisms - effect of contaminants from oil well produced water, 1 st edn. Elsevier Ltd, Amsterdam, pp 175-189

138. Neff JM (2002) Copper in the ocean. In: Bioaccumulation in marine organisms - effect of contaminants from oil well produced water, 1st edn. Elsevier Ltd, Amsterdam, pp 145-160

139. Shen W, Li Y, Qi T et al (2018) Fluorometric determination of zinc(II) by using DNAzyme-modified magnetic microbeads. Microchim Acta 185:1-8

140. Wang J, Yu J, Wang X et al (2018) Functional ZnS:Mn(II) quantum dot modified with L-cysteine and 6-mercaptonicotinic acid as a fluorometric probe for copper(II). Microchim Acta 185:1-13

141. Marshall AT, Clode PL (2002) Effect of increased calcium concentration in sea water on calcification and photosynthesis in the scleractinian coral Galaxea fascicularis. J Exp Biol 205:21072113 
142. Potasznik A, Szymczyk S (2015) Magnesium and calcium concentrations in the surface water and bottom deposits of a river-lake system. J Elem 20:677-692. https://doi.org/10.5601/jelem.2015. 20.1.788

143. Morr S, Cuartas E, Alwattar B, Lane JM (2006) How much calcium is in your drinking water ? A survey of calcium concentrations in bottled and tap water and their significance for medical treatment and drug administration. Musculoskelet J Hosp Spec Surg 2:130-135. https://doi.org/10.1007/s11420-006-9000-9

144. Talling JF (2010) Potassium - a non-limiting nutrient in fresh waters ? Fr Rev 3:97-104. https://doi.org/10.1608/FRJ-3.2.1
145. Christensen EAF, Illing B, Iversen NS, Johansen JL, Domenici P, Steffensen JF (2018) Effects of salinity on swimming performance and oxygen consumption rate of shiner perch Cymatogaster aggregata. J Exp Mar Bio Ecol 504:32-37. https://doi.org/10. 1016/j.jembe.2018.04.002

146. Brasuel MG, Miller TJ, Kopelman R, Philbert MA (2003) Liquid polymer nano-PEBBLEs for cl- analysis and biological applications. Analyst 128:1262-1267. https://doi.org/10.1039/b305254k

147. Sumner JP, Aylott JW, Monson E, Kopelman R (2002) A fluorescent PEBBLE nanosensor for intracellular free zinc. Analyst 127: 11-16. https://doi.org/10.1039/b108568a 